\title{
VISIÓN Y PRÁCTICA DE LOS APORTES SOCIALES DE LOS EMPRESARIOS EN CHILE*
}

\author{
Magdalena Aninat Sahli \\ Universidad Adolfo lbáñez
}

\begin{abstract}
RESUMEN: Este estudio analiza la visión y práctica de los empresarios chilenos respecto de la filantropía y las inversiones sociales, bajo el supuesto de que son elementos necesarios para el fortalecimiento de la sociedad civil y hábitos sociales como la cooperación y la confianza. A partir de una encuesta a 41 líderes y miembros de grupos controladores de los principales grupos empresariales de Chile, se obtuvo información cualitativa respecto de la percepción e implementación de aportes sociales en cinco dimensiones: motivaciones, intenciones, beneficiarios, proceso de intercambio y resultados obtenidos. Con este levantamiento se contribuye a ponderar la relevancia que la filantropía tiene entre los empresarios, e identificar ciertas trabas y falencias institucionales, aspectos que, desde una visión multidimensional de la filantropía, son necesarios para construir una estimación del potencial de escalamiento que tiene el fenómeno en Chile.

Palabras ClaVE: filantropía, empresarios, aportes sociales, sociedad civil.

RECIBIDO: julio 2015; ACEPTADO: octubre 2015.

ClasificaCión JEL: D64, H24.
\end{abstract}

Magdalena Aninat S. Directora fundadora del Centro de Filantropía e Inversiones Sociales (CEFIS), Escuela de Gobierno de la Universidad Adolfo Ibáñez. Email: magdalena.aninat@uai.cl.

* Este estudio se realizó con motivo de la creación del CEFIS. La autora quiere agradecer la guía y el apoyo de Ignacio Briones, así como los comentarios realizados por los árbitros anónimos de Estudios Públicos. 


\title{
THE VISION AND PRACTICE OF SOCIAL CONTRIBUTIONS OF CHILEAN BUSINESS OWNERS
}

\begin{abstract}
The study analyzes the philanthropic and social investment vision and practice of Chilean business owners, under the premise that these are necessary elements for the strengthening of civil society and of social habits such as cooperation and trust. Starting from a survey applied to 41 leaders and members of controlling shareholders of the main business groups in Chile, the study presents qualitative information regarding their perception and implementation of social giving on five dimensions: motivation, intentions, beneficiaries, exchange process and results. The study means to be a contribution for assessing the relevance that philanthropy has among business owners and for identifying potential obstacles and institutional deficiencies, as these, from a multidimensional view, are necessary to build an estimation of the potential growth of philanthropy in Chile.
\end{abstract}

KEYWORDs: philanthropy, business owner, social investment, civil society.

RECEIVED: July 2015; ACCEPTED: October 2015.

JEL CLASSIFICATION: D64, H24.

\section{INTRODUCCIÓN}

a filantropía - definida por la Real Academia de la Lengua como amor al género humano - ha sido un fenómeno persistente en la historia del hombre y, pese a ello, difícil de conceptualizar desde el ámbito académico. Entendida como un fenómeno multidimensional, en ella concurren iniciativas y relaciones de personas y de organizaciones en las cuales surgen factores éticos, emocionales y cognitivos, así como procesos sociales, económicos y políticos, generándose efectos observables a nivel macro, medio y micro (Rey 2013a, 7).

El origen del término se remonta a la Atenas de Pericles del siglo V a.C., al concepto de philanthropia asociado a la divinidad. El diccionario filosófico de la academia platónica refiere el término a las buenas obras y a los hábitos correctos que emanan de la acción del amor a la humanidad, produciendo tanto beneficios para ella, como un estado de gracia o plenitud de conciencia al ser humano que las origina (Sulek 2010a, en Rey 2013a).

En la era moderna, el concepto se relaciona a virtudes cívicas - de justicia y beneficencia en Adam Smith, de benevolencia en David Hume- 
como elementos constitutivos de la sociedad. En el análisis contemporáneo, los conceptos de capital social, sociedad civil y tercer sector han incorporado nociones subyacentes al fenómeno de la filantropía. La colaboración y el sentido del deber con el prójimo, agentes motivadores de la acción altruista, se han identificado como factores que contribuyen a la formación de capital social, elemento necesario para la prosperidad de la economía de mercado (Fukuyama 1996, 384) y para el funcionamiento de la democracia (Putnam 1993, 185). Una forma esencial del capital social son las redes de compromiso cívico, y mientras más densas sean estas redes en una comunidad, más posible es que sus ciudadanos sean capaces de cooperar para beneficio mutuo (Putnam 1993, 173).

El análisis académico contemporáneo ha señalado límites y potencialidades de la filantropía en la construcción social. Si bien se le reconoce a la filantropía un rol colaborador en el desarrollo y fortalecimiento de la sociedad civil (Irarrázaval y Guzmán 2008, 331), en un sentido estrictamente cuantitativo se reconoce que nunca estará en condiciones de ofrecer suficientes recursos materiales y humanos para transformar las sociedades latinoamericanas en términos de la distribución del ingreso, alivio a la pobreza o progreso social. No obstante, se le asigna un papel cualitativo para impulsar el cambio social como catalizador, dinamizador y constructor de modelos: en la difusión e innovación de modelos sociales escalables y en mejorar la efectividad y productividad de los programas sociales existentes (Coatsworth 2008, 10-11).

En Chile, la filantropía ha sido un fenómeno de estudio esporádico, en el que la escasez y dispersión de datos disponibles ha dificultado un análisis sistemático. El estudio histórico rescata la tradición de beneficencia y asistencia a las necesidades básicas de la población en condiciones de vulnerabilidad, con una importante influencia de la Iglesia Católica. En el siglo XIX, la limosna universal da paso a la caridad focalizada, organizada en instituciones y asociaciones, principalmente en contextos urbanos y con un carácter eminentemente moralizador (Ponce de León 2011, 17). A medida que, hacia finales del siglo, la "cuestión social" pone de relevancia las necesidades de la población en condición de vulnerabilidad, el Estado secularizado va adquiriendo un papel más activo en la provisión e institucionalización de la asistencia social. Durante el siglo XX, van cobrando protagonismo la beneficencia privada no sólo relacionada con la aristocracia lati- 
fundista, sino también con asociaciones de profesionales y administrativos, sociedades laicas y de clase media, al tiempo que se fortalecen las redes de voluntariado femenino y las fundaciones en el ámbito de la educación, la asistencia a la pobreza, la cultura y la salud, muchas de las cuales han prevalecido en el tiempo. El sistema de Estado asistencial demuestra, sin embargo, su incapacidad de suplir todas las demandas sociales y confirma la necesidad de establecer una relación de cooperación con las organizaciones de la sociedad civil (Machado 2010, 10). La adopción de un modelo de libre mercado y un Estado subsidiario introduce hacia fines de la década de 1980 incentivos tributarios a la participación de la empresa privada en distintos ámbitos del desarrollo social, incorporándola como agente donante en la provisión de bienes públicos, rol que se incorpora en la tendencia de responsabilidad social empresarial y, en forma más reciente, en el concepto de valor compartido (Porter y Kramer 2011, 4-5).

Desde principios de la década de 1990 se ha registrado un incremento en la variedad de las instituciones e iniciativas filantrópicas en Latinoamérica, y en las expectativas acerca de lo que la filantropía organizada puede lograr en la sociedad, ya sea por sí sola o en alianzas con otras fuerzas. Debido, en parte, al crecimiento de la riqueza, a los procesos de democratización política y al desarrollo de la sociedad civil se ha constatado un florecimiento de la filantropía empresarial, el voluntariado organizado y la creación de fundaciones donantes y operadoras de programas, así como también de las redes y asociaciones nacionales de donantes (Sanborn y Portocarrero 2008, 13-14).

Si bien no existe una agencia pública que disponga ni realice un informe de las donaciones sociales totales en Chile, ni tampoco un registro público de donantes, donatarios o fundaciones filantrópicas que permita estimar el universo total de aportes sociales que año a año se realizan en el país, la información entregada por el Servicio de Impuestos Internos (SII) muestra que en Chile las donaciones registradas y acogidas a las principales leyes de incentivos tributarios han tenido un significativo crecimiento en el tiempo. Si se toma exclusivamente la variación de los aportes acogidos a las leyes de incentivos tributarios a las donaciones con fines deportivos, sociales, culturales, educacionales, a universidades o a instituciones sociales — las principales leyes 
de incentivos tributarios- ${ }^{1}$, se refleja un aumento de 97 por ciento del monto de las donaciones entre los ejercicios tributarios de los años 2008 y 2014 (gráfico 1), lo que va acompañado de un aumento de 143 por ciento del número total de contribuyentes que realizan estas mismas donaciones (de 8.673 contribuyentes en 2008 a 21.158 en 2014).

El país ha experimentado un crecimiento de la riqueza que se ve reflejado no sólo en el hecho de haber duplicado el PIB per capita entre los años 2004 y 2010, sino también en el incremento de individuos de alto patrimonio que tiene el país. ${ }^{2}$ Sin embargo, con un ejercicio que considera el monto total de donaciones acogidas a las principales leyes de incentivos tributarios del año 2013 (que sumó 132.497 millones de pesos nominales) es posible determinar que éste representa el 0,12 por ciento del Producto Interno Bruto de ese año, ${ }^{3}$ lejos aún del promedio de 2 por ciento que muestra Estados Unidos (Giving USA Report 2014).

${ }^{1}$ Se incluyen las donaciones acogidas a los siguientes marcos legales: Art. $46^{\circ}$ del Decreto Ley n. ${ }^{\circ}$ 3.063, de 1979, para donaciones efectuadas a determinados establecimientos educacionales e instituciones traspasados a las municipalidades; Art. $31^{\circ} \mathrm{n} .^{\circ} 7 \mathrm{de}$ la ley sobre impuesto a la renta para donaciones efectuadas a programas de instrucción básica o media gratuita, técnica, profesional o universitaria en el país, ya sean privados o fiscales, donaciones hechas a los Cuerpos de Bomberos de la República, al Fondo de Solidaridad Nacional, al Servicio Nacional de Menores y a los Comités Habitacionales Comunales; Art. $3^{\circ}$ de la Ley n. ${ }^{\circ} 19.247$, de 1993, para donaciones con fines educacionales; Art. $8^{\circ}$ de la Ley n. ${ }^{\circ} 18.985$, de 1990 , sustituida por la Ley n. ${ }^{\circ} 20.675$, de 2013, para donaciones con fines culturales; Ley n. ${ }^{\circ} 19.885$, de 2003, a instituciones que prestan servicios directos a personas de escasos recursos o discapacitadas y del fondo mixto de apoyo social; Art. $62^{\circ}$ y siguientes de la Ley n. ${ }^{\circ}$ 19.712, de 2001, para donaciones con fines deportivos; Art. $69^{\circ}$ de la Ley n. ${ }^{\circ} 18.681$, de 1987, para donaciones destinadas a universidades e institutos profesionales.

2 Según cifras de Global Wealth 2014, Boston Consulting Group, la cantidad de hogares millonarios en el mundo, es decir, con activos líquidos invertibles sobre un millón de dólares, alcanzó los 16,3 millones de hogares, un salto importante respecto de los 13,7 millones de 2012. Al mismo tiempo, el segmento de más de 100 millones de dólares en Chile está representado por 65 hogares, que poseen el 18 por ciento de la riqueza total del país, versus una participación promedio del 13 por ciento en América Latina.

${ }^{3}$ Cifra aproximada: se calcula en base a montos de donaciones acogidas a las leyes señaladas en el gráfico 1 realizadas en el ejercicio tributario del año 2013 según datos entregados por el Servicio de Impuestos Internos frente al Producto Interno Bruto (PIB) del mismo año. Otras estimaciones han cifrado las donaciones en Chile en torno al 0,27 por ciento del PIB correspondiente al año 2005 (Rivera 2010). Estas estimaciones son parciales, ya que es posible que existan otras legislaciones con incentivos a las donaciones y otras donaciones que estos cálculos o el sistema no registran. 
Gráfico 1. MONTO DE DONACIONES (EN MM\$) SEGÚN LEGISLACIONES QUE SE ESPECIFICAN

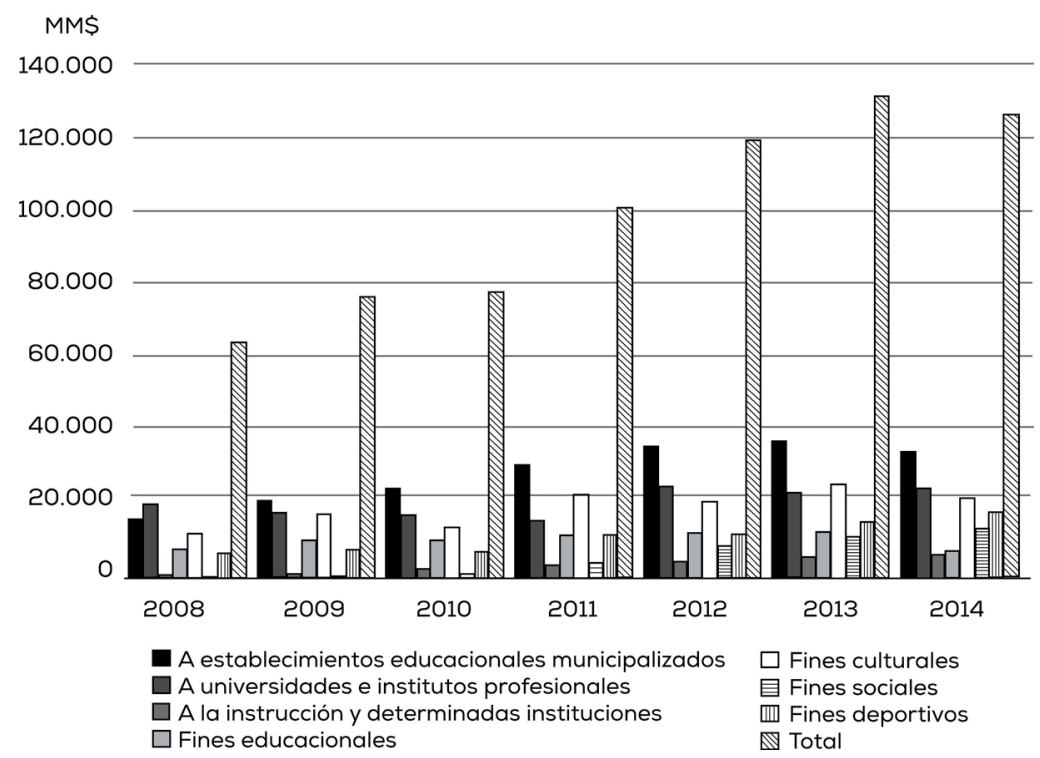

Nota: Cifras nominales.

Fuente: CEFIS UAI 2015, en base a información entregada por el Servicio de Impuestos Internos entre marzo-mayo de 2015. Los años corresponden a ejercicios tributarios.

Las donaciones privadas son reconocidas como un fenómeno complejo, definidas por múltiples factores relacionados con las normas, tradiciones y valores culturales, así como por los marcos institucionales en los cuales operan los donantes y las organizaciones sin fines de lucro (Sokolowski 2012). Construir una estimación del potencial de escalamiento que tiene la filantropía en Chile requiere incorporar a las variables económicas e institucionales (crecimiento de la riqueza, aumento de donaciones registradas, marco legal), dimensiones del ámbito ético, emocional y cognitivo propio de la práctica de sus actores.

\section{OBJETO DE ESTUDIO}

Si bien el ecosistema de filantropía involucra a una serie de actores (donantes, agentes de la sociedad civil, en tanto donatarios, y al Estado en tanto regulador de las donaciones), este estudio busca contribuir con 
un análisis microsocial cualitativo de los individuos de alto patrimonio y propietarios de los principales grupos empresariales en Chile, en tanto agentes filantrópicos, reales o potenciales.

Recoger información y analizar la visión de quienes no sólo son "dueños del capital", sino también líderes o miembros de los principales grupos empresariales respecto de sus aportes a organizaciones con fines de desarrollo social es especialmente relevante en el contexto chileno, donde diversas legislaciones establecen incentivos tributarios a las donaciones para los contribuyentes del impuesto de primera categoría. Por otra parte, las prácticas de responsabilidad social empresarial y la presión ciudadana respecto del desarrollo de proyectos productivos han impulsado un crecimiento de las inversiones sociales corporativas, especialmente en las llamadas "comunidades de impacto".

El objeto del presente trabajo radica en estudiar el fenómeno filantrópico desde la visión mutidimensional del concepto (Rey 2013a, 12), que se construye sobre motivaciones (¿por qué?), intenciones (¿para qué?), beneficiarios (¿para quién?), el proceso de intercambio (¿cómo, cuánto, dónde?) y resultados obtenidos (¿qué?). Esta visión reivindica la interpretación de la filantropía desde el ámbito moral, que hace hincapié en el carácter voluntario de los aportes privados en pro del bien público, acorde a valores éticos como la caridad, la generosidad, la solidaridad o la participación cívica, con resultados tanto trascendentes como tangibles y donde es necesario un componente de altruismo, ya que el donante no espera obtener un retorno para sí comparable al valor de su aporte (Rey 2013b, 181-182).

El análisis relacionado con motivaciones y comportamiento hizo recomendable aproximarse al objeto de estudio en base a, por una parte, entrevistas personales, estructuradas, $y$, por otra, a tomadores de decisión pertenecientes a los principales grupos empresariales, sin formular una hipótesis cerrada a comprobar. El estudio busca obtener información cualitativa, que contribuya a ponderar la relevancia que la filantropía tiene entre los empresarios e identificar su visión de las trabas y ciertas falencias institucionales, dimensiones que, desde una visión multidimensional del fenómeno, son necesarias de considerar en una estimación del potencial de escalamiento que tiene la filantropía en Chile. 


\section{METODOLOGÍA}

Se definió un universo que cumpliera cuatro consideraciones generales:

1) que incorporara a los principales grupos económicos del país;

2) que cubriera una diversidad de ámbitos empresariales;

3) que incorporara a empresarios que cuentan con fundación filantrópica o han sido donantes activos en organizaciones de fines sociales, y

4) que se basara en información pública que contemplara empresas que, además del grupo controlador, incluyeran propiedad de otros accionistas. ${ }^{4}$

En base a estas consideraciones, para la construcción del universo se utilizó como fuente inicial de información el listado de grupos empresariales que reporta la Superintendencia de Seguros y Valores (SVS), ${ }^{5}$ en el cual se identificaron 67 grupos empresariales de propiedad chilena o propiedad mixta, excluyéndose a aquellos grupos de propiedad internacional. Esta cohorte se cotejó luego con el ranking de grupos económicos 2014 del Centro de Estudios en Economía y Negocios de la Universidad del Desarrollo, donde se identificaron cinco grupos económicos que no contemplaba el informe de la SVS, los que se incorporaron al universo junto con tres grupos empresariales relevantes en términos de patrimonio y aportes sociales no incorporados en los listados anteriores. Con ello, el universo sumó un total de 75 grupos económicos.

Entre el 8 de octubre de 2014 y el 31 de enero de 2015 se realizaron 41 entrevistas $^{6}$ a miembros relevantes en la toma de decisiones de dichos grupos empresariales (GE), para lograr una tasa de cobertura del 55 por ciento del universo definido (tabla 1).

Todos los entrevistados están vinculados a la propiedad o grupo controlador de las empresas y en su mayoría ocupan posiciones relevantes en la toma de decisiones al interior de los grupos empresariales (gráfico 2).

\footnotetext{
${ }^{4}$ Se buscaba recoger el rol de las empresas respecto de los aportes sociales en situaciones en que el control es compartido con otros accionistas.

${ }^{5}$ Grupos económicos que reportan a la SVS a mayo de 2014, ver en: http:// www.svs.cl/portal/principal/605/w3-propertyvalue-18651.html.

${ }^{6}$ Ver Anexo 1 con listado de entrevistados.
} 
Tabla 1. DATOS UNIVERSO Y MUESTRA

\begin{tabular}{lcc}
\hline Datos universo & Universo & Muestra \\
\hline $\begin{array}{l}\text { Subtotal grupos empresariales de propiedad } \\
\text { privada nacional o mixtos que reportan a la } \\
\text { SVS }\end{array}$ & 67 & 36 \\
$\begin{array}{l}\text { Cantidad de grupos empresariales ranking } \\
\text { UDD no incluidos en SVS }\end{array}$ & 5 & 3 \\
$\begin{array}{l}\text { Otros GE relevantes y con acciones de filan- } \\
\text { tropía }\end{array}$ & 3 & 2 \\
\hline Total grupos empresariales & 75 & 41 \\
\hline Representatividad & $100 \%$ & $55 \%$ \\
\hline
\end{tabular}

La muestra tiene un perfil demográfico diverso en su composición etaria: el 12 por ciento de los entrevistados son mujeres y 88 son hombres; el 24 por ciento son menores de 50 años, mientras que el 57 por ciento está entre 51 y 70 años, y 19 por ciento tiene entre 71 y 85 años. Los ámbitos empresariales a los cuales están vinculados son amplios, con predominio de los sectores financiero ( 24,7 por ciento), industrial (20 por ciento) e infraestructura (17,6 por ciento).

Gráfico 2. PRINCIPAL CARGO EMPRESARIAL ENTREVISTADO

(ADEMÁS DE SU PARTICIPACIÓN COMO ACCIONISTA MAYORITARIO O EN EL GRUPO CONTROLADOR DEL GRUPO ECONÓMICO)

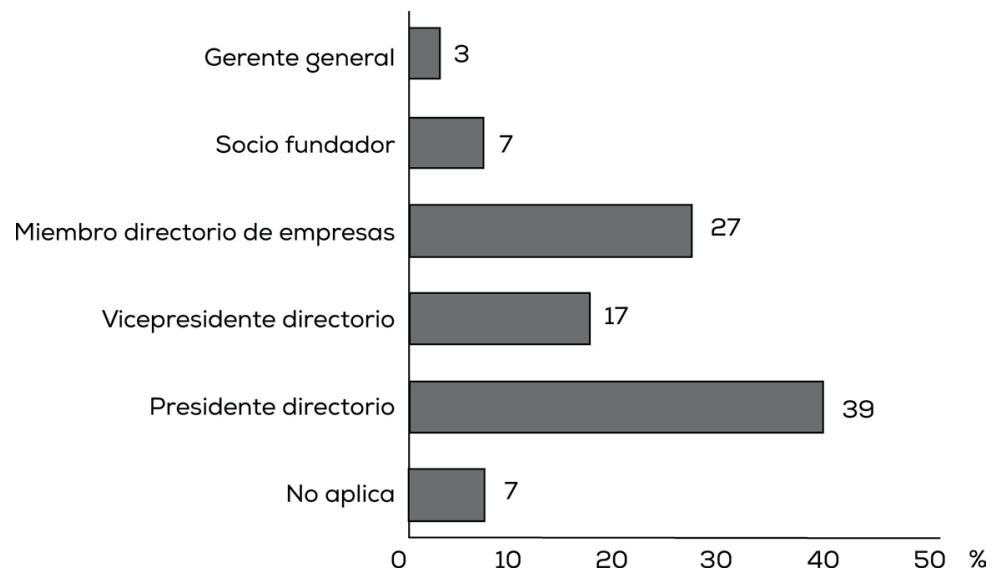

Fuente: CEFIS UAI 2015. 
Las entrevistas se realizaron en base a un cuestionario estructurado, aplicado en forma personal en encuentros de un promedio de 55 minutos de duración. ${ }^{7}$ A los entrevistados se les aseguró la confidencialidad de lo conversado, dado que las respuestas no serían vinculadas a cada persona en particular.

El cuestionario se elaboró en base a tres estudios similares (Noonan y Rosquetta 2008; Berger et al. 2004; y HICS y UBS 2015), siguiendo la guía de un grupo $a d h o c^{8}$ de profesionales vinculados a la investigación y práctica de la filantropía y con el apoyo especial del Hauser Institute de la Harvard University. Además de las preguntas demográficas, el cuestionario constó de 27 preguntas base, ${ }^{9}$ de las cuales 10 tienen estructura de respuestas abiertas y 17 corresponden a preguntas que inducen a respuestas cerradas, relacionadas con las dimensiones del concepto filantrópico adoptado en el objeto de estudio (motivaciones, intenciones, beneficiarios, proceso de intercambio y resultados obtenidos, además de preguntas sobre la percepción del marco institucional).

Para su análisis posterior, las entrevistas fueron transcritas y analizadas para identificar percepciones y prácticas de los entrevistados. La información fue clasificada de acuerdo a los temas del cuestionario e indexada en una tabla de contenido, asociando respuestas a los grupos de temas y subtemas, identificando reiteraciones del mismo comentario entre distintos entrevistados. Esto permitió sistematizar las respuestas y agruparlas conceptualmente en series de entre 2 a 10 categorías de respuestas tipo según cada pregunta. ${ }^{10}$

Dada la escasa literatura y discusión pública en Chile respecto de este campo, existía un interés por levantar las denominaciones que utilizan los empresarios evitando sesgar sus respuestas. Por ello, en el

${ }^{7}$ En algunos casos, por problemas de tiempo, algunas preguntas no fueron aplicadas a los entrevistados (se señala el detalle en los resultados).

${ }^{8}$ Participaron: Paula Doherty Johnson, senior research fellow Hauser Institute, Harvard University; Ignacio Briones, decano Escuela Gobierno, Universidad Adolfo Ibáñez; Ricardo González, coordinador de opinión pública, Centro Estudios Públicos; Jorge Larraín, empresario y académico; Armando Holzapfel, gerente Fundación Chile + Hoy; Mario Valdivia, empresario; Felipe Medina, miembro del comité de filantropía de Goldman Sachs y presidente del directorio de Give to Colombia.

${ }^{9}$ En el caso de los entrevistados que lideran fundaciones personales, familiares o con terceros, se incorporó un anexo de siete preguntas específicas. Estructura del cuestionario en Anexo 2.

${ }^{10}$ Los resultados recogen patrones y tendencias presentados en porcentajes que se complementan con una selección de comentarios de los empresarios recogidos durante las entrevistas. 
cuestionario se utilizó el concepto genérico de "aportes sociales", entendido como donaciones o inversiones cuyo objetivo es el desarrollo de la sociedad, y no se entregaron definiciones a priori de los conceptos asociados al tema de estudio (filantropía e inversiones sociales).

\section{RESULTADOS}

El estudio agrupa en tres ámbitos los resultados obtenidos:

1) motivaciones, intenciones y beneficiarios, incluyendo en este ámbito la relación entre filantropía y confianza empresarial pública;

2) proceso de intercambio y resultados obtenidos: recoge la práctica de aportes respecto de una serie de variables que permiten identificar compromiso e involucramiento y manejo de instrumentos de medición de resultados, y

3) marco institucional, acotado en este trabajo a la visión del empresario respecto del marco de incentivos tributarios a las donaciones vigente en Chile.

\subsection{Motivaciones, intenciones y beneficiarios}

\subsubsection{El rol social de la empresa y el empresario}

Dado el objeto de estudio enfocado a los dueños de las empresas, en primer término se recogió la visión general que tienen estos actores respecto del rol de los empresarios y de las empresas en tanto actores del desarrollo social.

Los entrevistados reconocen un cambio de mentalidad en cuanto al concepto de empresa ("de lo que me enseñaron en la universidad"), a través de la incorporación de variables de inversión social en la creación de valor para los accionistas. El concepto de valor compartido con los stakeholders (Porter y Kramer 2011, 4-5) ${ }^{11}$ y de la empresa como

11 Mientras la visión neoliberal señala que la empresa no debe invertir en necesidades sociales sino concentrarse en maximizar el valor para los accionistas, Porter y Kramer plantean que las necesidades sociales, y no sólo las económicas convencionales, son las que definen los mercados. El concepto de valor compartido va más allá de la retribución a la sociedad, y propone incorporar en las políticas y las prácticas operacionales de la empresa estrategias que se hagan cargo de las limitaciones de la sociedad (como, por ejemplo, las insuficiencias en educación), y en especial de sus stakeholders y el entorno donde operan, como parte de la estrategia de productividad y expansión de mercados. 
actor social que contribuye más allá de la generación de empleos, bienes o servicios se manifiesta ante la pregunta de si las empresas deben o no deben hacer aportes sociales. El 41 por ciento de los entrevistados afirma que las empresas deben realizar aportes como parte de sus estrategias de sustentabilidad o de responsabilidad social empresarial (RSE). Y ante la pregunta: “¿Está usted de acuerdo o no está de acuerdo con que los empresarios tienen un rol social que cumplir o el deber de 'devolver a la sociedad'?", el 51 por ciento de los entrevistados manifestó estar de acuerdo.

Dos ejemplos de respuestas:

Con el tiempo ha ido aumentando esta conciencia del rol social. Ahora es más evidente, más común. En parte, las comunidades te obligan a tomar contacto, establecer apoyo, porque hay proyectos que se quedan parados. La realidad ha hecho cambiar mucho a los empresarios y tender hacia allá.

(Presidente de directorio de empresa)

La primera responsabilidad social que tiene un empresario es administrar bien sus empresas, generar valor para la sociedad. Dicho lo anterior, su responsabilidad abarca todos los ámbitos y relaciones que tiene con los stakeholders, básicamente con los accionistas, los colaboradores y sus familias, los clientes, los proveedores y la sociedad o comunidades con las cuales se desenvuelve (...). Las empresas, como ciudadanos o parte de una sociedad, tienen una responsabilidad además de las anteriores de contribuir al desarrollo educacional, cultural, social y de todo orden, de las comunidades de la sociedad en las cuales nos desenvolvemos. Esas cualidades implican no sólo ser buenos ciudadanos y cumplir con las leyes, sino efectuar un aporte efectivo a que esas comunidades se desarrollen y progresen.

(Presidente de directorio de empresa)

Con todo, el 44 por ciento de los entrevistados comenta que la filantropía no es propia de las empresas. Subyace en este subgrupo un reconocimiento a una lógica transaccional en los aportes corporativos, en la cual los aportes sociales son utilizados por las empresas como una herramienta de legitimación (Chen et al. 2008, 141), para la viabilidad y 
desarrollo de proyectos o mejora de reputación. Es interesante reconocer que este subgrupo diferencia los aportes sociales corporativos de la filantropía, que no busca retorno ni monetario ni simbólico y cuya toma de decisiones se realiza a nivel personal o familiar:

Hay que distinguir la responsabilidad social empresarial, que básicamente está en manos de las empresas y que la incorporan como parte de su política de relaciones con la comunidad o marketing. En mi criterio, eso no es filantropía. Eso forma parte de la labor de las empresas de insertarse bien en la comunidad, de tener una marca potente; es parte de su función maximizadora del valor de la empresa. Entonces, para mí, y lo hemos tenido claro en nuestras empresas, la filantropía es lo que hacen los dueños de las empresas, sus fundaciones familiares, lo que hacen personalmente, el compromiso personal en la gestión.

(Presidente de directorio de un grupo empresarial, dirige una fundación empresarial y una fundación con terceros)

En las empresas, las que son cerradas, no tienes problemas para donar. Pero, ¿cómo vas a donar cuando tienes otros accionistas? Por ejemplo, donar a la Iglesia Católica si hay accionistas que pueden ser judíos o musulmanes. Tú no puedes imponer. Las donaciones las tiene que hacer cada persona.

(Presidente de directorio de grupo empresarial, participa en fundación)

\subsubsection{Motivaciones para donar}

Consultados sobre la motivación para realizar aportes sociales, el bien común (deber moral de devolver a la sociedad) y la tradición familiar predominan sobre la necesidad de invertir en los trabajadores y stakeholders relacionados al desarrollo de la empresa, factor que ocupa el tercer lugar en importancia de las motivaciones (gráfico 3).

Las razones que subyacen a la obligación moral de "devolver a la sociedad o al país" están combinadas con la búsqueda de resultados — "dar oportunidades" e "igualar la cancha" - y con las experiencias personales que marcaron el progreso económico familiar: 
Gráfico 3. ¿POR QUÉ RAZONES REALIZA APORTES SOCIALES, CUÁL ES SU MOTIVACIÓN?

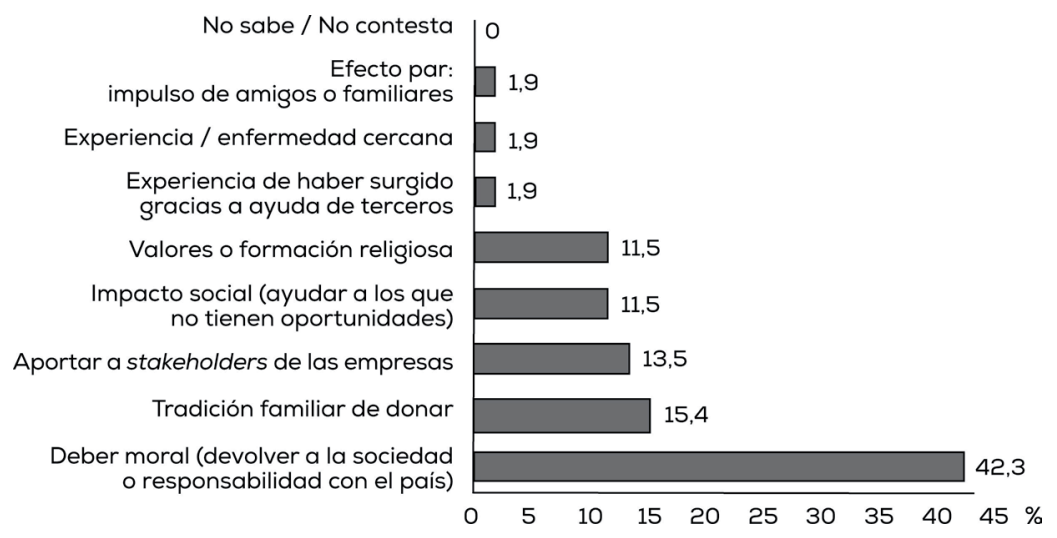

Nota: El 27 por ciento de los entrevistados entregó dos razones. Los porcentajes se calculan sobre el total de respuestas.

Fuente: CEFIS UAI 2015.

Los aportes sociales de mi familia tienen que ver con esta actitud de devolver la mano. Mi abuelo y mi tío abuelo eran inmigrantes que llegaron a Chile con sus platitas, les fue bien, recibieron aquí una tremenda acogida y un bienestar que probablemente los mantuvo a ellos en estado de deuda de tratar de devolver la mano de estos beneficios recibidos.

(Presidente de directorio de un grupo empresarial, dirige una fundación empresarial y una fundación con terceros)

A mí me incomoda vivir en una sociedad muy desigual. (...) Y todavía en el empresariado hay gente que, con esa mirada del pasado, piensa que el Estado debe preocuparse de lo social mientras nosotros producimos. Yo no he creído nunca en eso. Me incomoda vivir en un país en que la gente tenga problemas severos y que no puedan tener igualdad de oportunidades de verdad.

(Miembro de directorio de un grupo empresarial, preside fundación)

Es interesante señalar que, pese a que el 90 por ciento de los entrevistados profesa una religión, las motivaciones religiosas quedan relegadas al quinto lugar, una tendencia similar a lo que ocurre a nivel internacional (Bishop y Green 2009, 57). Si bien, la religión y la fe 
formaron parte del desarrollo histórico de la filantropía en Chile y Latinoamérica y continúan influenciando a ciertas personas, los principios de caridad, solidaridad se han internalizado y convertido en valores familiares y personales, más que mandatos de doctrina religiosa (HICS y UBS 2015, 31).

Por otra parte, ningún empresario menciona los incentivos tributarios como una motivación para realizar aportes sociales y, sin embargo, como se verá en el ámbito del marco institucional, se recoge una visión crítica respecto del sistema vigente en Chile.

\subsubsection{Autoconcepto}

En el ámbito de los aportes sociales, el estudio indica una difícil articulación de su autoconcepto. ${ }^{12}$ Se preguntó a los empresarios sobre su propia identificación en el rol de aportes filantrópicos en base a tres alternativas: como persona que hace caridad, que hace filantropía o inversionista social, sin asociar definiciones específicas a cada una de estas categorías ex profeso, con el fin de levantar definiciones desde sus propios comentarios, y recoger información respecto de las intenciones de los empresarios en sus aportes sociales. El gráfico 4 muestra que el 63,4 por ciento de la cohorte no se identifica con ninguna de las categorías. Es interesante señalar que la mitad de este subgrupo participa en una fundación u organización filantrópica.

Con todo, los entrevistados sí entregan una definición por omisión: ninguno se identifica con el concepto de caridad, concepto que se entiende ligado a una donación reactiva ("dar el cheque"), sin hacer seguimiento al aporte en términos de resultados inmediatos y resultados de impacto. Por ejemplo:

Como familia, en el pasado éramos caritativos y ya no queremos ser caritativos. Estamos ordenándonos ahora para hacer inversionistas sociales, tenemos que llegar a hacer algo como familia que tenga un impacto real en la sociedad. Es filantropía, pero más inte-

12 Autoconcepto se entiende como la percepción que el individuo tiene de sí mismo, la cual se basa directamente en sus experiencias en relación con los demás y en las atribuciones que él mismo hace de su propia conducta (Shavelson, Hubner y Stanton 1976, 411). 
ligente. Es eso porque no pides nada a cambio (...). Ha habido una evolución. En la experiencia que me ha tocado vivir, ya dejamos de ser las familias caritativas, donde éramos muy buenos para la caridad. Levantabas una piedra y había una fundación, y la cantidad de gente que llega a esta oficina a pedir tiene que ver mucho con la caridad, con dar un cheque y no medir el resultado. (...) Hoy se está determinando una línea editorial en los grupos. Y, por otro lado, ahora somos una sociedad con más conciencia social.

(Director de empresas)

El 36,6 por ciento de los empresarios que se identifica con algún concepto (filantropía o inversionista social) señala que sus aportes van acompañados de algún tipo de seguimiento, involucramiento directo o, bien, búsqueda de impacto o transformación social. Por ejemplo:

Más que nada me identifico como una persona que hace filantropía. Caridad no, esa palabra no va con mi pensamiento ni con el de mi familia. Uno quiere lograr cosas. Caridad es hacer un cheque. Nosotros, en cambio, todo lo que hacemos es involucrarnos, ponernos en el lugar del otro.

(Directora de empresa, preside una fundación familiar)

No soy filántropo ni tampoco soy una persona que hace caridad. Soy inversionista social porque trato de enseñar a pescar más que dar pescado.

(Director de empresas, preside una fundación familiar)

Gráfico 4. ¿CÓMO SE DEFINE USTED EN EL ÁMBITO DE LOS APORTES SOCIALES? (ALTERNATIVAS CERRADAS)

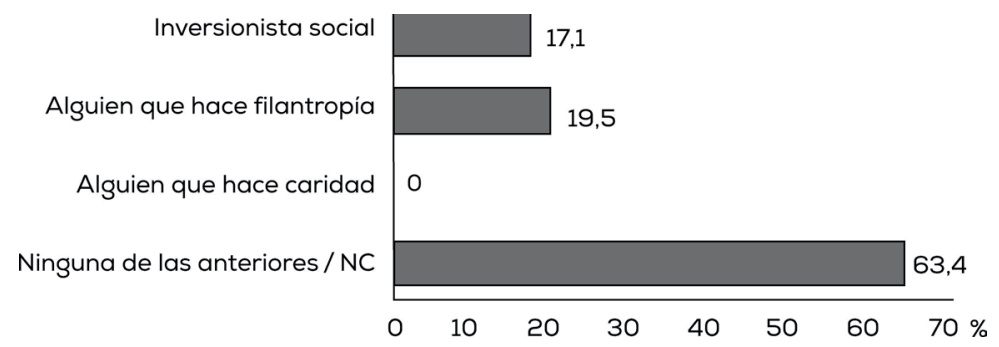




\subsubsection{Filantropía y opinión pública}

Diversos estudios de opinión pública reflejan la baja percepción y confianza de la ciudadanía respecto del sector empresarial. ${ }^{13}$ Se preguntó a los empresarios sobre la relación entre filantropía y la confianza hacia los empresarios (gráfico 5) dada la relación que se ha estudiado entre filantropía y legitimidad social de las empresas (Chen et al. 2008, 134).

Gráfico 5. ¿CREE USTED QUE UN DESARROLLO DE LA FILANTROPÍA Y LAS INVERSIONES SOCIALES EN CHILE TENDRÍA O NO TENDRÍA UN IMPACTO EN LA CONFIANZA HACIA LOS EMPRESARIOS?

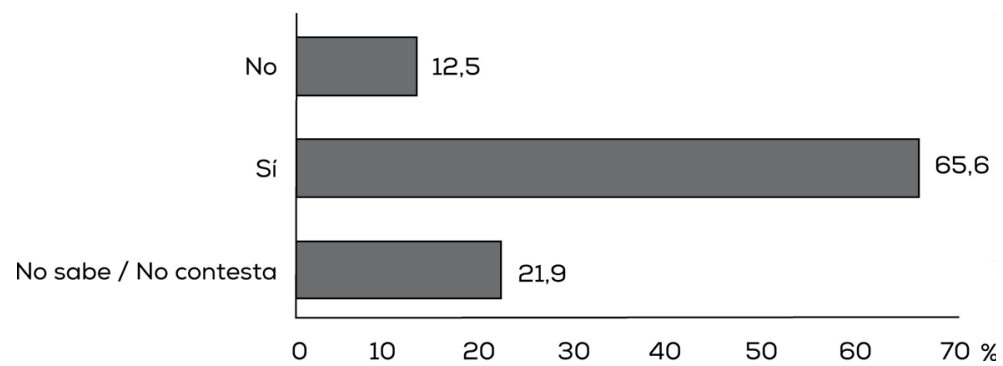

Nota: Por escasez de tiempo, esta pregunta se aplicó al 88 por ciento de los entrevistados. Los porcentajes se calculan sobre el total de entrevistados a los cuales sí se les formuló la pregunta.

Fuente: CEFIS UAI 2015.

La visión generalizada respecto de la positiva relación entre desarrollo de la filantropía y generación de confianza hacia el mundo empresarial se señala con ciertos resguardos. Por ejemplo:

Definitivamente ayudaría a generar más confianza, pero en la medida en que donar sea cada vez más profesional, porque cala más hondo, llega más a fondo a los temas. Yo creo que, muchas veces, el profesionalismo que tienen los empresarios para el 90 por ciento de sus cosas no lo tienen en este ámbito.

(Director de empresas, preside fundación familiar)

13 Según la Encuesta Nacional Bicentenario, las personas que manifestaban tener mucha y bastante confianza hacia las empresas se redujo de 16 a 8 por ciento entre los años 2006 y 2015 (Universidad Católica y GFK Adimark 2015). 
Hay que tener cuidado cómo se hacen esas cosas. Si se interpreta como lavado de imagen desgraciadamente podría jugar en contra. (Presidente de directorio de empresa)

Es interesante señalar que esta positiva relación entre filantropía y confianza empresarial también es manifestada por la ciudadanía. ${ }^{14}$

\subsubsection{Percepción sobre los beneficiarios}

La totalidad de los empresarios entrevistados ha tenido o mantiene contacto con organizaciones donatarias, ya sea a través de las solicitudes de aportes sociales o de la participación en gobiernos corporativos de organizaciones sin fines de lucro. Sin embargo, la percepción del nivel profesional de las organizaciones sin fines de lucro a nivel general es bajo (gráfico 6), aunque se tiende a distinguir entre las "grandes" organizaciones (aquellas con mayor trayectoria) y el resto, donde se percibe un bajo nivel de administración.

Gráfico 6. ¿CUÁL ES SU OPINIÓN RESPECTO DEL NIVEL PROFESIONAL QUE TIENEN LAS ORGANIZACIONES SOCIALES SIN FINES DE LUCRO EN CHILE?

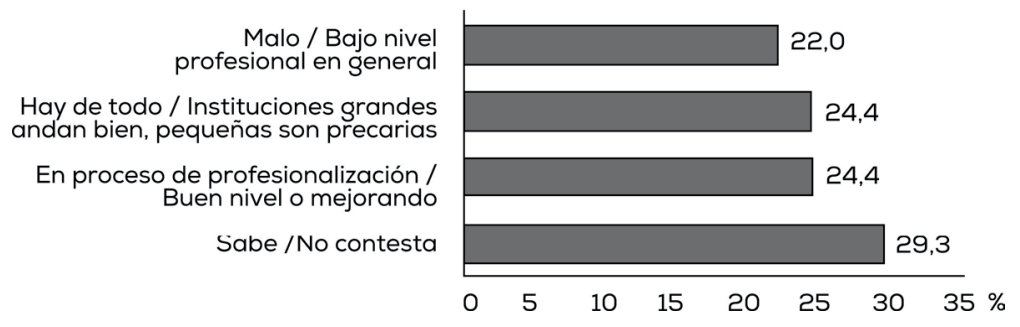

Fuente: CEFIS UAI 2015.

A nivel general, los entrevistados hacen mención de una marcada disociación entre las prácticas y herramientas del mundo empresarial

${ }^{14}$ A nivel de la ciudadanía, el 60 por ciento de las personas estima que es positivo que los empresarios contribuyan con donaciones a áreas sociales como educación, salud pobreza o cultura; y el 65 por ciento señala que un aumento significativo de las donaciones a temas sociales mejoraría la imagen de los empresarios, mientras que el 27 por ciento afirma que no cambiaría nada su imagen pública y sólo el 4 por ciento dice que empeoraría su imagen (Estudio de Opinión Pública de Donaciones Empresariales, CEFIS UAI 2015) 
(accountability, transparencia, gestión profesional, auditorías, planificación) con las prácticas y herramientas de las organizaciones de la sociedad civil:

Tengo que pensar en el impacto, en cuánta gente voy a impactar. Pero esto no es obvio para muchas instituciones. Nadie se los ha transmitido, no tienen visión estratégica. Me junto con fundaciones y no tienen modelo de negocios, no tienen plan estratégico, y es básico para la sustentabilidad a largo plazo. Les hablas de modelo de negocio y se ponen incómodos. Pero aunque sea sin fines de lucro tienen que tener un plan de negocios para reinvertir.

(Directora de empresas, preside fundación familiar)

Son totalmente voluntaristas; personas con una voluntad y espíritu admirable, pero no funciona. No me ha tocado que se roben la plata, pero se ve en la ineficiencia, en cuánto llega al beneficiario final: en vez de atender a 100, pueden atender sólo a 20.

(Director de empresa)

Esta baja confianza en las capacidades de organizaciones de la sociedad civil —una realidad compartida por la filantropía en Latinoamérica- está influenciada por los bajos índices de confianza social (HICS y UBS 2015, 24), y constituye para los empresarios una traba para aumentar la escala de donaciones y un incentivo a crear estructuras propias, en un esquema de filantropía operativa más que de donaciones a organizaciones existentes.

La percepción deficiente o regular del nivel profesional de las organizaciones sociales sin fines de lucro contrasta con la visión optimista que tienen respecto de una nueva generación de líderes con alto grado de compromiso social y preparación profesional, que están liderando organizaciones sociales que buscan doble retorno - social/ medioambiental y económico, en el modelo de las Benefit Corporations o Empresas B- ${ }^{15}$ o bien organizaciones sin fines de lucro con nuevos modelos de desarrollo, en algunos casos replicando modelos internacionales (gráfico 7).

15 Según información entregada por Sistema B (http://www.sistemab.org/), desde el año 2012 a marzo de 2015, se han certificado 76 organizaciones como empresa B en Chile y otras 750 están en proceso. 
Gráfico 7. RESPECTO DE LOS EMPRENDEDORES SOCIALES, ¿CREE USTED QUE SUS INICIATIVAS TENDRÁN O NO TENDRÁN IMPACTO EN SOLUCIONAR DESAFÍOS SOCIALES QUE TIENE EL PAÍS?

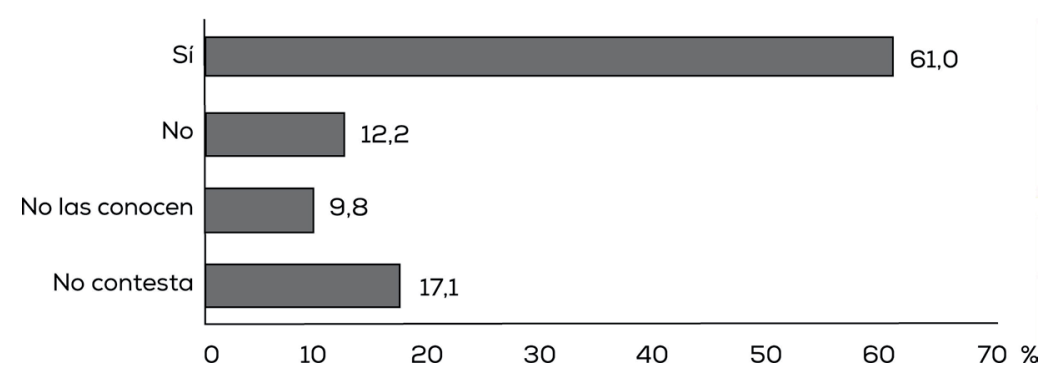

Fuente: CEFIS UAI 2015.

Aunque sólo el 15 por ciento conoce directamente a emprendedores sociales o ha invertido en ellos, existe una visión generalmente optimista de este nuevo modelo de doble retorno. Por ejemplo:

La gracia que yo le veo a los emprendimientos sociales es que inviertes para montar una empresa que después va a ser autosustentable, que vas a financiar y luego va a seguir adelante. A eso le encuentro valor, porque el resto de las cosas en que haces un aporte para algo después se muere. Es otra mentalidad, tiene fin de lucro, pero con un sentido.

(Socio fundador de empresa)

Los fondos de inversión social, que invierten exclusivamente en organizaciones que tienen un doble retorno, constituyen otro instrumento de canalización de las inversiones de impacto. ${ }^{16}$ Sin embargo, entre los empresarios existe desconocimiento y bajo nivel de aceptación de este tipo de instrumentos (gráfico 8). ${ }^{17}$

${ }^{16}$ El concepto "inversiones de impacto", acuñado en 2007, se refiere a instrumentos de inversión donde convergen valores y modelo de negocios, para aunar los objetivos sociales y medioambientales con la rentabilidad del capital (Rodin y Brandenburg 2014, 4).

${ }^{17}$ El año 2010 se creó en Chile el primer Fondo de Inversión Social, dependiente de Ameris Capital, con un monto de 4,5 millones de dólares a diez años, con un retorno objetivo de UF $+2 \%$ anual y un aumento cuantificado del impacto social de los proyectos (que se mide usando la métrica internacional GIIRS). 
Gráfico 8. ¿CONOCE O HA INVERTIDO EN FONDOS DE INVERSIÓN DE IMPACTO?

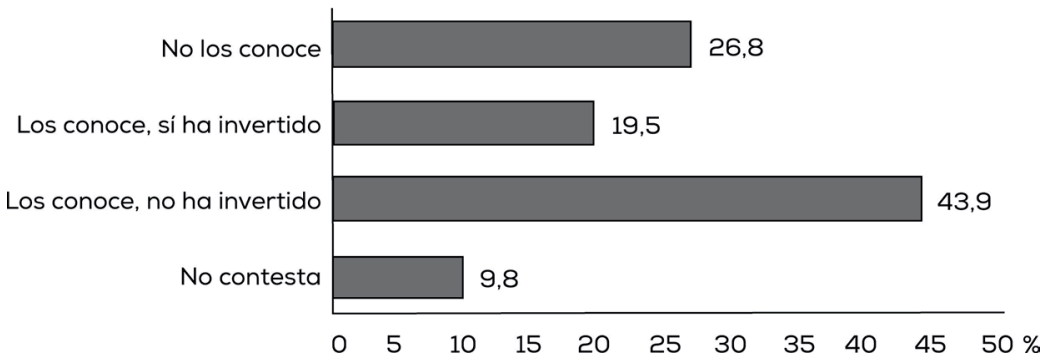

Fuente: CEFIS UAI 2015.

Quienes sí han invertido reconocen la ventaja del doble objetivo, aplicando análisis financieros al ámbito social y sin la necesidad de administrar organizaciones propias. Por ejemplo:

Creo que es una manera de que la inversión sea profesionalizada y con un doble sentido: primero, que sea sustentable financieramente, $y$, segundo, que haya alguien que lo esté administrando y le haga seguimiento. Para una persona que quiera aportar sin armar una gran estructura, me parece interesante invertir en un fondo así; hace un aporte con un proceso articulado.

(Socio fundador de empresa)

\subsection{Proceso de intercambio y resultados obtenidos}

El total de los entrevistados afirma realizar aportes filantrópicos y su percepción es que se trata de una práctica generalizada a nivel del grupo empresarial.

En el proceso de intercambio, el estudio caracteriza su práctica buscando elementos que permitan identificar el nivel de compromiso y de interiorización como parte sustantiva del desarrollo empresarial o familiar. Para ello se busca determinar:

1) El compromiso a nivel familiar a través del involucramiento de miembros de la familia en la toma de decisiones de los aportes - o la creación de fundaciones familiares-, además de la disposición a donar parte de la herencia. 
2) El involucramiento personal directo en la toma de decisiones respecto de los aportes, y la realización de aportes no financieros (como participación en gobierno corporativo en organizaciones de la sociedad civil).

3) La disposición al reconocimiento público, ya que genera un efecto entre pares y en la opinión pública.

En el análisis del proceso de intercambio se buscó también identificar variables relacionadas con una práctica estratégica, que logra que los aportes sean incidentes en el desarrollo social. Estas variables se refieren a:

1) Identificación de un foco de destino de los recursos, lo que si bien no permite asumir que se ha hecho investigación de campo o se ha elaborado una teoría de cambio, es un paso inicial para ese proceso.

2) Institucionalización de protocolos o estructuras en los canales que se utilizan para realizar los aportes sociales, lo que permite inferir cuán sistemática es la práctica de donaciones.

3) Sistema de definición de presupuesto filantrópico, variables para la toma de decisiones y rango de montos.

4) Medición de resultados y de impacto para conocer el efecto real de la transformación lograda por las donaciones, más allá del reporte de cumplimiento de actividades y de utilización de recursos.

\subsubsection{Percepción sobre sus pares}

Si bien el total de los entrevistados afirma realizar aportes filantrópicos, consultados respecto de sus pares, el 58,5 por ciento de ellos afirma que es una práctica generalizada entre los empresarios hacer aportes sociales (gráfico 9).

Aunque las respuestas se basan en el conocimiento de su círculo social, como explícitamente lo mencionan los entrevistados, también destaca el hecho de que no siempre es de conocimiento público:

Es una práctica mucho más habitual de esta segunda generación que de la generación anterior que generó las "lucas". Puede ser porque antes había mucho menos plata en este país, lo que indudablemente influye.

(Presidente de empresa, director de fundación familiar) 
Gráfico 9. EN SU VISIÓN, ¿CUÁN GENERALIZADA ES LA PRÁCTICA DE REALIZAR APORTES SOCIALES FILANTRÓPICOS POR PARTE DE LOS EMPRESARIOS CHILENOS?

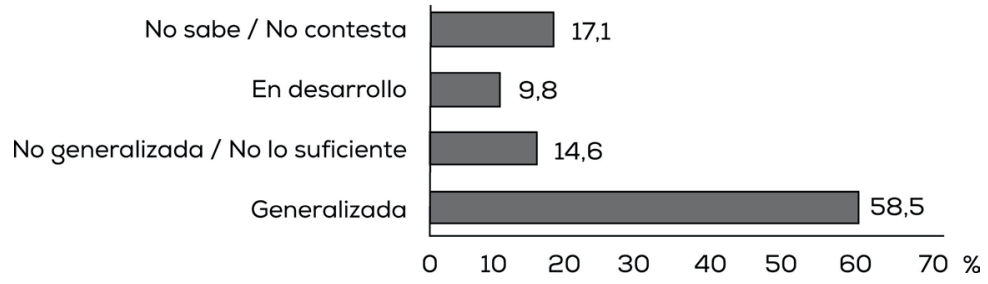

Fuente: CEFIS UAI 2015.

Se dona más de lo que se sabe, bastante más, pero con los incentivos correctos, esto podría ser aún más relevante.

(Presidente de empresa, director de fundación familiar)

Por otra parte, existe la percepción entre los empresarios de que los aportes no se realizan de forma estratégica (es decir, no habría medición de resultados o análisis previo de la institución beneficiaria) y, al mismo tiempo, de que los montos involucrados son poco relevantes respecto del tamaño de los patrimonios:

En Chile se picotea. Te llama el cura de la fundación X pero nadie se mete a ver si la fundación $\mathrm{X}$ está bien administrada. Es la plata más el involucramiento lo que hace falta. Cuando el mundo empresarial se involucra en organizaciones sociales hace la diferencia. Pensar que el donante no solo dé aportes, sino que también involucre a ejecutivos en la administración podría hacer una gran diferencia. Y eso no es para nada generalizado (...). Diría que hay una práctica generalizada, pero no en los montos que debieran ser para el nivel de desarrollo que hemos alcanzado. Tampoco es una práctica sistemática. La idea de la filantropía en Chile debiera avanzar hacia una práctica en los family offices, donde en el manejo del patrimonio estén evaluándose los montos filantrópicos al igual que el resto de las inversiones. (Miembro de directorio familiar, presidente de fundación)

La visión de los empresarios contrasta con la percepción que tiene la ciudadanía. Según el Estudio de Opinión Pública de Donaciones Em- 
presariales $^{18}$ (CEFIS UAI 2015), las donaciones de las personas se perciben más altas que las de las empresas y la de los empresarios, aportes que más del 50 por ciento de los encuestados percibe como bajas o muy bajas (gráfico 10).

Gráfico 10. PERCEPCIÓN PÚBLICA DE DONACIONES.

DE ACUERDO A LA INFORMACIÓN QUE USTED MANEJA, ¿HOY LAS DONACIONES QUE HACEN LAS PERSONAS / LOS EMPRESARIOS / LAS EMPRESAS PARA AYUDAR A SOLUCIONAR LOS PROBLEMAS SOCIALES EN CHILE SON...?

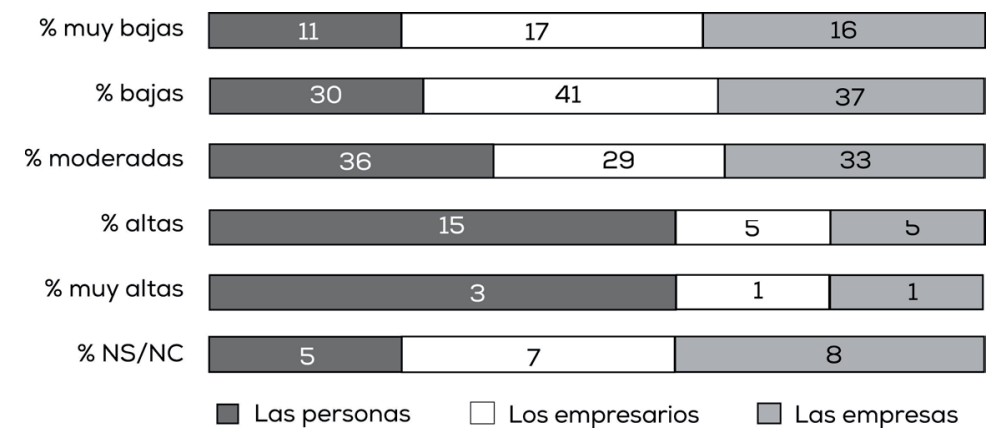

Fuente: Estudio de Opinión Pública de Donaciones Empresariales (CEFIS UAI 2015).

\subsubsection{Involucramiento de la familia, herencia y participación directa}

En Chile, entre los años 2004 y 2012, las empresas controladas por familias representaron el $56 \%$ del total de las empresas abiertas en la Bolsa de Santiago (Durán 2015). La familia constituye un factor relevante en el mundo empresarial chileno, pero no sólo en el desarrollo de negocios sino también en los aportes filantrópicos. De hecho, la generosidad - vinculada a acciones de tipo altruista - es un valor exclusivo de las empresas de propiedad familiar (Ceja et al. 2010, 18).

Entre los entrevistados, el 80 por ciento afirma tener o estar vinculado a una empresa familiar, el 95 por ciento está casado y el 96 por

${ }^{18}$ Encuesta ciudadana de representación nacional (margen de error de $+/-3,7$ puntos porcentuales al 95 por ciento de confianza), realizada en julio de 2015 por el Centro de Filantropía e Inversiones Sociales de la Escuela de Gobierno de la Universidad Adolfo Ibáñez (CEFIS UAI 2015). 
ciento tiene al menos un hijo. En los ámbitos de los aportes sociales, la familia cumple un rol fundamental en la motivación y proceso de toma de decisiones. Como se señaló anteriormente, la tradición familiar es el segundo factor de motivación para realizar aportes sociales. Mientras el total de los entrevistados afirma estar involucrado personalmente en la toma de decisiones de los aportes, sólo el 28,6 por ciento lo hace individualmente, mientras que el 51 por ciento dice participar al incluir a algún familiar, sea cónyuge, hijos, hermanos o padres (gráfico 11).

En el contexto familiar, existe una creciente incorporación de los hijos en los aportes sociales y una consciencia transversal sobre el rol de este instrumento como vehículo para facilitar o fortalecer vínculos familiares. El 46 por ciento de los empresarios declara que sí ha incorporado a sus hijos - aunque la profundidad del involucramiento varía de un mero "están informados" a una participación en una estructura formal como una fundación familiar-, mientras que el 20 por ciento señala estar en proceso de incorporarlos. El 34 por ciento de los entrevistados cuenta con una fundación familiar, y en tres ocasiones señalaron que la creación de esta estructura filantrópica había sido parte de una estrategia ex profeso para incorporar a nuevas generaciones (menores de 35 años) en la formación de los valores familiares y el fortalecimiento de vínculos intergeneracionales. Por ejemplo:

Gráfico 11. ¿CON QUIÉN TOMA SUS DECISIONES ACERCA DE SUS APORTES SOCIALES?

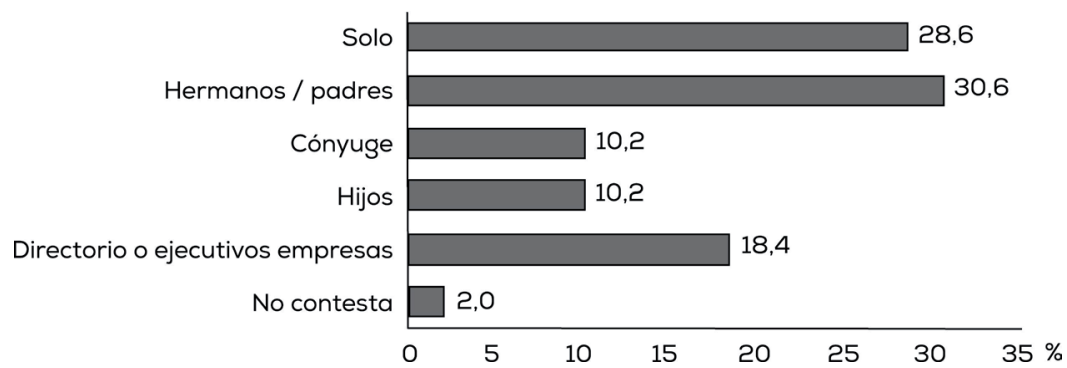

Nota: El 20 por ciento de los entrevistados señaló dos tipos de personas con las que toma sus decisiones. Los porcentajes se calculan sobre el total de respuestas.

Fuente: CEFIS UAI 2015. 
Creo que la principal ventaja de tener nuestra fundación ha sido familiar, porque participan todos los hijos y es una instancia muy enriquecedora para juntarse y no hablar de las empresas, sino para hablar de cómo dar.

(Director de empresas, líder de fundación familiar)

Donar como parte de la herencia es otro factor que históricamente en Chile - y a nivel comparado - se ha convertido en instrumento de construcción de legados relevantes en el ámbito social, cultural o educacional. Los entrevistados manifiestan distintos grados de disposición a donar su herencia (gráfico 12).

Las trabas que mencionan aquellos que han considerado donar su herencia se relacionan con la falta de un contexto tributario y legal que facilite el proceso de donación, la reducida libre disponibilidad del patrimonio a legar - con menciones críticas a la legislación vigente en Chile que regula la disposición de la herencia - y con la carencia de instituciones confiables para administrar la donación.

Creo que hay que revisar la ley de herencia. En los orígenes esta ley buscaba proteger al grupo familiar. Cuando se hizo esta ley, Chile era extremadamente pobre y no había las fortunas que hay hoy. Creo que hay que actualizarla, dejar la misma ley para patrimonios inferiores a determinado monto, pero para la gente que

Gráfico 12. ¿HA CONSIDERADO DONAR A FINES SOCIALES EN SU HERENCIA?

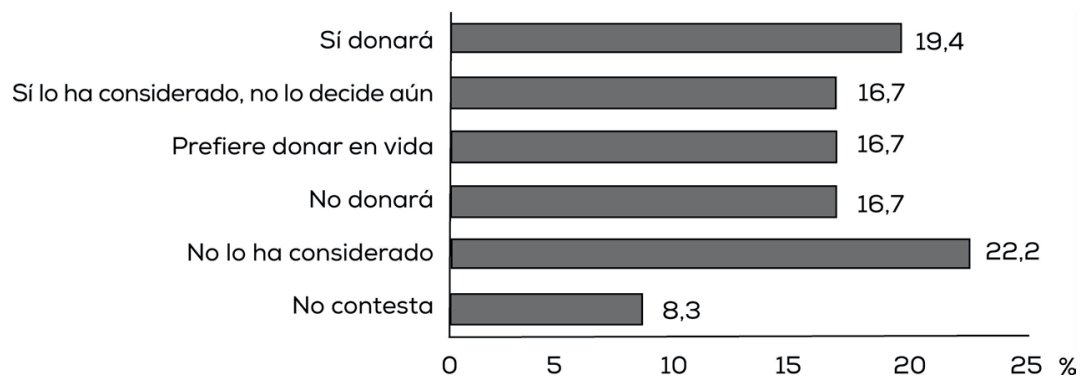

Nota: Por escasez de tiempo, esta pregunta se aplicó al 88 por ciento de la muestra. Los porcentajes se calculan sobre el total de entrevistados a los cuales sí se les formuló la pregunta.

Fuente: CEFIS UAI 2015. 
tiene varios millones de dólares, debiera existir un mayor grado de libertad. ¿Por qué esa persona no puede dejar su herencia donde le dé la gana? Es un tema de debate de un país que ha progresado, que es próspero, que tiene fortuna. Es parte de la libertad de las personas.

(Socio fundador de empresa)

Por otra parte, los recursos que los empresarios identifican como aportes sociales relevantes no sólo se relacionan con financiamiento, sino también con transferencia de capacidades en términos de gestión. El 66 por ciento de los entrevistados señala realizar aportes no financieros a través de la participación en directorios de fundaciones propias, de terceros o de la sociedad civil; en algunos casos, en más de una entidad.

\subsubsection{Anonimato versus reconocimiento}

En países como Estados Unidos, donde la filantropía y los aportes sociales representa el 2 por ciento del PIB y los aportes financieros o en trabajo voluntario son una práctica cultural generalizada, el reconocimiento público —o la emulación colectiva de la práctica filantrópica (Sorman 2014, 93) - constituye uno de los ejes de la masa crítica sobre el cual se basa un ecosistema que incita a una práctica generalizada de donaciones sociales. En Chile, la tendencia al anonimato ha sido una práctica común, de raíces históricas y religiosas (Rivera 2010, 37), una práctica que mantiene el 36,6 por ciento de los entrevistados (gráfico 13).

Las razones que señalan los empresarios que optan por el anonimato son diversas, pero sólo uno menciona razones religiosas, mientras que el resto apela a la idiosincrasia local, la formación familiar o evitar el resentimiento de familiares lejanos. Por ejemplo:

Esto tiene una raíz cultural católica del pasado. A nadie le gusta figurar porque a uno después lo marcan con el dedo que es caritativo y se portó mal en esa otra cuestión.

(Socio fundador de empresa)

Yo opto por el anonimato. ¿Por qué? Porque es una especie de pudor a que la gente interprete que me estoy comprando una imagen. (Socio fundador de empresa) 
Gráfico 13. RESPECTO DE LA DIFUSIÓN O RECONOCIMIENTO TRAS SUS APORTES SOCIALES, ¿USTED OPTA POR...?

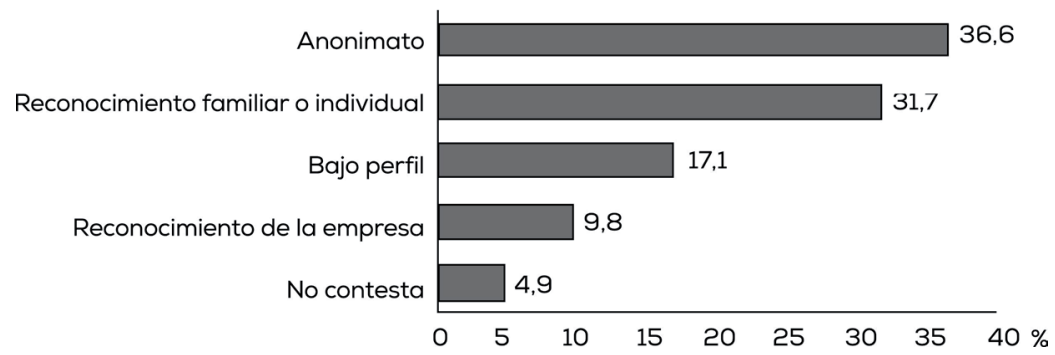

Fuente: CEFIS UAI 2015.

Sin embargo, el 58,6 por ciento de los entrevistados admite estar dispuesto a algún tipo de reconocimiento, ya sea de bajo perfil, a nombre de las empresas o bien a título familiar o individual. Entre este grupo se reconoce una cierta "necesidad" de difusión, ya sea asociada a legitimación social o, bien, en busca de un efecto de influencia sobre sus pares, como sucede en países anglosajones:

Tiene sus bemoles y costos tremendos, pero hay que involucrarse y dar a conocer que uno está participando, en forma cuidadosa, sin andar pontificando. Pero sólo así se genera confianza.

(Director de empresas, presidente de fundación)

\subsubsection{Foco de destino de los aportes filantrópicos}

Los empresarios manifiestan claridad respecto de sus ámbitos de interés en términos sociales: todos los entrevistados cuentan con al menos un ámbito de necesidad social ya definido al cual entregan sus aportes sociales. Sin embargo, el grado de profundidad con que esta definición enmarca sus aportes sociales es variable, y se visualiza más sistemático entre aquellos que cuentan con una estructura formalizada (como fundaciones).

La educación y la salud históricamente han sido áreas donde la iniciativa filantrópica ha sido relevante en la provisión de servicios a poblaciones en condición vulnerable. Los dos ámbitos, pero en especial la educación, siguen ocupando un espacio fundamental en las prioridades de los empresarios para destinar sus donaciones (gráfico 14). 
Gráfico 14. PRINCIPALES FOCOS O ÁMBITOS DE DESTINO DE LOS APORTES DE LOS EMPRESARIOS

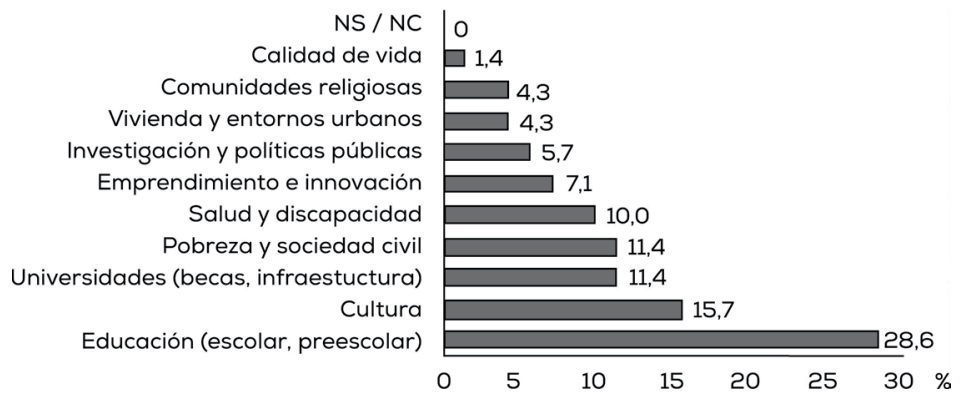

Nota: El 58 por ciento de los entrevistados señaló solo un ámbito, mientras que el 17 por ciento señaló dos ámbitos, el 20 por ciento tres ámbitos y el 5 cuatro ámbitos. Los porcentajes de cada ámbito se calculan sobre el total de respuestas.

Fuente: CEFIS UAI 2015.

La educación escolar y preescolar $(28,6$ por ciento) y la cultura $(15,7$ por ciento) son los ámbitos prioritarios de destino de los aportes sociales de los empresarios, prioridades que difieren de la opinión de la ciudadanía. ${ }^{19}$ Sin embargo, un tercio de los aportantes a cultura señala que ésa es un área de relevancia en tanto aporta a la formación de las personas, es decir, en relación con la educación. Si se suma a ello el aporte a universidades en becas o infraestructura universitaria ${ }^{20}(11,4$ por ciento), el ámbito educacional-cultural en su conjunto constituye el foco principal de los aportes de los empresarios:

Es difícil separar educación de cultura. Se dice que un país es más culto cuando es más educado. Finalmente tiene que ver con que la educación apunta a tus primeros años de aprendizaje y la cultura es aprendizaje de toda tu vida. Y nosotros buscamos es-

${ }^{19}$ Esta priorización contrasta con la percepción ciudadana recogida en Estudio de Opinión Pública de Donaciones Empresariales (CEFIS UAI 2015). Los ciudadanos priorizan como destino de las donaciones empresariales la salud y/o discapacidad (60 por ciento), la educación escolar y preescolar (51 por ciento), seguida por la superación de la pobreza (38 por ciento), innovación y emprendimiento (15 por ciento). Sólo en sexto lugar están las universidades (11 por ciento) y en séptimo y último lugar la cultura ( 8 por ciento).

${ }^{20}$ Se separa aportes al ámbito escolar y preescolar del ámbito universitario, ya que cuentan con regulación de incentivos tributarios diferentes. 
tablecer un cambio conductual en personas que creemos que podemos agregarles valor a sus habilidades y competencias durante sus primeros años de vida.

(Director de empresa, preside fundación familiar)

Creo que este país tiene una carencia de educación muy grande, principalmente en el acceso a la educación de calidad como la puede tener un niño en un colegio privado: si naciste en La Dehesa tu vida está asegurada y si naciste en La Pincoya estás bien jodido y eso nadie lo ha solucionado. Yo he tratado de aportar en eso.

(Director de empresas)

Áreas que recientemente han adquirido relevancia social, como la innovación y el emprendimiento, las políticas públicas y la investigación, aparecen también entre las prioridades de destino de los aportes al desarrollo del país. Por otra parte, uno de los menores índices corresponde al aporte a comunidades religiosas (4,3 por ciento), pese a que el 90 por ciento declara profesar una religión y varios entrevistados mencionan participar en organizaciones dirigidas por sacerdotes católicos a través de aportes financieros o en sus directorios. Asimismo, los ámbitos que no aparecen mencionados son aquellos relacionados con los denominados derechos civiles como tampoco la conservación medioambiental, ámbitos donde la actuación de fundaciones filantrópicas internacionales ha sido especialmente relevante en Chile.

\subsubsection{Estructuras y canales de aportes}

Existe una diversidad de visiones respecto de los mejores canales para realizar los aportes sociales de los empresarios. El 15 por ciento de los empresarios realiza aportes en tres niveles en forma paralela: a) aportes directos a organizaciones, emprendedores sociales o fondos de inversión social; b) participa o lidera una fundación familiar o con terceros; y c) cuenta con sistemas de aportes sociales en las empresas en las cuales participa en la propiedad (gráfico 15).

Las empresas son el canal más extendido de aportes sociales, una realidad compartida a nivel latinoamericano, donde se detecta una dis- 
Gráfico 15. CANALES PRINCIPALES UTILIZADOS PARA LOS APORTES FILANTRÓPICOS

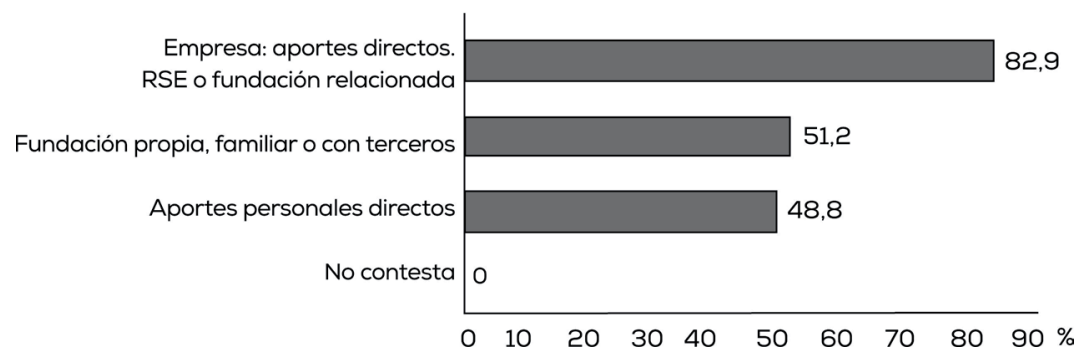

Nota: El 32 por ciento de la muestra señaló un solo canal, mientras que el 54 indicó dos canales y el 15 , tres canales principales para la realización de sus aportes sociales. Se calcula sobre el total de entrevistados, por lo que suma más de 100 por ciento.

Fuente: CEFIS UAI 2015.

tinción poco precisa entre filantropía privada y corporativa (HICS y UBS 2015, 26). Los empresarios chilenos señalan distintos grados de institucionalización de sus aportes corporativos: el 25 por ciento dice que en sus empresas existe un protocolo o sistema formal que involucra al directorio o a la gerencia y otro 25 por ciento tiene una fundación relacionada con la empresa. Por ejemplo:

La ventaja de tener una fundación es tener un foco, colocar gente que está en la administración de la empresa y que tiene conocimiento y maneja bien los recursos. Les da a ellos una motivación social adicional al trabajo que realizan.

(Socio fundador, en proceso de crear fundación corporativa)

No tenemos fundación propia en la empresa. Se discutió y se decidió apoyar a otras instituciones ya existentes. Habiendo fundaciones que saben hacer su pega, nosotros podemos aportar como empresa al trabajo que ellos saben hacer.

(Director de empresa)

Es relevante la tasa de institucionalización de los aportes sociales a nivel personal y familiar: el 51 por ciento de los entrevistados está involucrado en una fundación propia, familiar o con terceros. Entre las ventajas de contar con una estructura de este tipo, señalan un mejor control 
del destino de los recursos, la focalización, mirada de largo plazo y gestión profesional, además de ser una vía que facilita la incorporación de las nuevas generaciones en el caso de las fundaciones ligadas a familias empresarias:

Nosotros hicimos nuestra fundación principalmente para ordenar los recursos, si no sería un despelote. Por la ley era súper complicado hacer donaciones, pero con una fundación tienes mucha más libertad para entregarle a la gente. Además, le pusimos más estructura, un equipo y todo ello te ayuda a formalizar una serie de procesos. Entonces, cuando tienes una fundación, tienes más posibilidades de que las lucas sean bien canalizadas.

(Presidente de directorio, participa en fundación familiar)

Sin embargo, entre aquellos que no cuentan con una fundación predomina la idea de que éstas requieren de estructuras burocráticas y sólo se justifica en caso de montos altos:

¿Por qué no crear una fundación dentro de la familia como la nuestra? Es imposible. No son montos que justifiquen una fundación. Tendría que hacer una administración, balances, mandar la información a los ministerios de Economía y de Justicia. ¿Para qué? ¿Qué ganaría respecto de lo que ya hacemos y funciona?

(Director de empresas)

\subsubsection{Presupuesto filantrópico}

La confianza en el líder y en la organización, el profesionalismo de la gestión, la sustentabilidad de los proyectos y el reporte de resultados obtenidos son las principales variables que los empresarios señalan tener en consideración a la hora de decidir la entrega de un aporte a solicitudes de organizaciones sociales.

Sin embargo, la decisión respecto del monto global destinado a aportes con fines sociales se toma en base a una amplia diversidad de variables (ver gráfico 16).

Existe una renuencia a revelar el presupuesto destinado a aportes sociales. Ante la pregunta por el monto de los aportes (rango promedio de los últimos tres años), los entrevistados revelan distintos tipos de 
Gráfico 16. FACTORES QUE INFLUYEN EN LA DEFINICIÓN DEL MONTO DE LOS APORTES

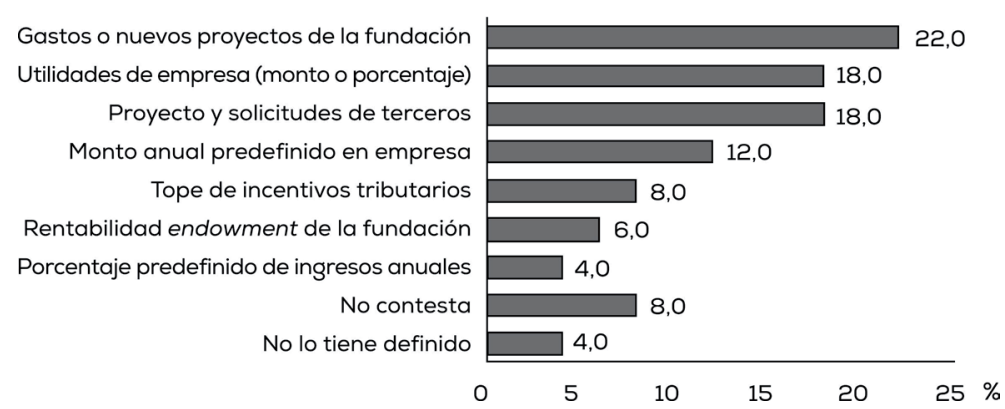

Nota: El 22 por ciento de los entrevistados indicó dos factores; el 2 por ciento tres factores. Este planteamiento no se aplicó por falta de tiempo al 5 por ciento de los entrevistados. Los porcentajes se calculan sobre el total de respuestas.

Fuente: CEFIS UAI 2015.

cifras: presupuesto anual de la fundación (lo que incluye en algunos casos también ingresos propios, además de las donaciones), donaciones personales o familiares anuales, o cifra de un aporte significativo a un proyecto específico de una sola vez (por ejemplo, destinado a un endowment o la construcción de infraestructura), o bien aportes a nivel de empresa, cuando éste es el principal canal de distribución de los aportes (gráfico 17).

Si bien el 22 por ciento de los entrevistados no reveló rango de montos específicos, es posible inferir que aquellos que estuvieron dispuestos a revelarlos y a la vez cuentan con una fundación invierten montos mayores que aquellos que lo hacen a nivel personal o de empresa sin una estructura formal filantrópica (gráfico 18):

El monto está marcado por el tope que nos permite la ley a nivel de empresas, pero también influye la calidad del proyecto y la inversión respecto del gasto corriente involucrado en nuestra fundación familiar. Ese gasto tiene que ser sustentable en el tiempo. Acá, en la empresa, puede haber años malos y no puede estar en riesgo la continuidad de la fundación.

(Presidente de directorio de empresa, participa en fundación familiar) 


\section{Gráfico 17. EMPRESARIOS QUE REVELAN MONTOS DE APORTES SOCIALES}

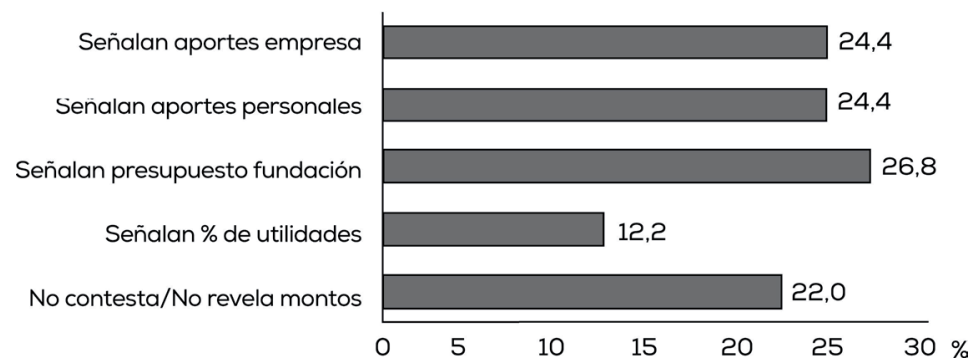

Nota: El 10 por ciento de los entrevistados reveló más de un origen de monto de aportes (monto que entrega a nivel de empresa y fundación familiar o bien monto y porcentajes de utilidades de la empresa). Los porcentajes de respuestas se calculan sobre el total de entrevistados, por lo que suman más de 100 por ciento

Fuente: CEFIS UAI 2015.

Gráfico 18. CUÁL ES EL MONTO ANUAL PROMEDIO QUE HA DESTINADO A APORTES SOCIALES DURANTE LOS ÚLTIMOS TRES AÑOS?

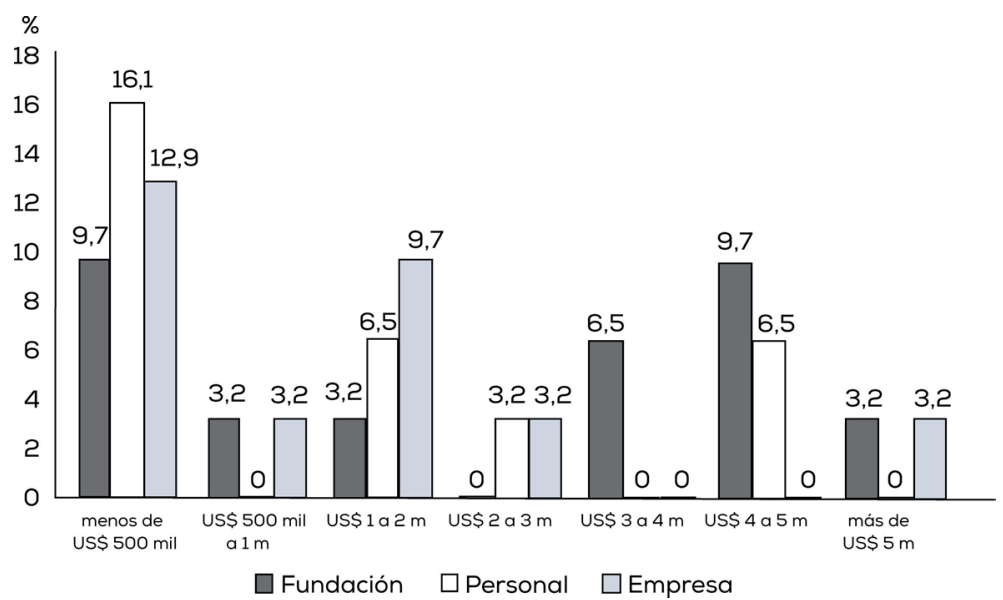

Nota: Las respuestas se calculan sobre el subgrupo de entrevistados que reveló algún tipo de monto, esto es el 76 por ciento del total de los entrevistados. Se excluye de este subgrupo a aquellos que entregaron un porcentaje, pero no un monto. El 2 por ciento de los entrevistados reveló montos a nivel empresa y a nivel de fundación familiar.

Fuente: CEFIS UAI 2015. 
Destaca el 12,2 por ciento de empresarios que señala tener predefinido un porcentaje anual de sus ingresos:

Tengo una idea de lo que estoy dispuesto a dar y los ingresos del año. Lo defino así: un monto al año, que es el 10 por ciento de los ingresos anuales que tengo, un número que creo que es alto.

(Director de empresas, participa en fundación con terceros)

\subsubsection{Evaluación de resultados y medición de impacto}

Conocer si realmente los montos invertidos están cumpliendo su objetivo, transformando la vida de una persona o una comunidad, requiere un sistema de medición de resultados e impacto que vaya más allá del cumplimiento de actividades, una práctica incorporada en las corrientes de filantropía estratégica y especialmente vinculada al "filantrocapitalismo" (Bishop y Green 2009, 18), propias del perfil de filántropos-empresarios que utilizan el enfoque de management en sus donaciones. En una lógica de recursos insuficientes para los objetivos de cambio social definidos, este tipo de práctica no sólo permite optimizar lo invertido, sino también analizar cuánto de ello llega efectivamente al beneficiario final. Ello se realiza a través de mecanismos de medición de resultados que permiten determinar variables de costo por retorno social (SROI en su sigla en inglés). Los mecanismos de medición de resultados también facilitan al donante una evaluación ex ante frente a un proyecto o entidad, no sólo respecto a su eficiencia administrativa, sino también respecto de su capacidad para lograr efectivamente el objetivo o cambio final preestablecido según experiencias anteriores propias o de terceros. Sin embargo, en el ámbito local, ni la práctica de las mediciones de resultado ni la conciencia de su relevancia aparecen muy generalizadas (gráfico 19).

El subgrupo que sólo hace seguimiento de actividades desecha otro nivel de estudios más profundos, debido al costo asociado o por estar en desacuerdo con esta práctica:

Nosotros exigimos entregar resultados numéricos y planes de trabajo. Si no hay feedback de eso se corta la línea de acción. Pero no he visto evaluación de impacto y discrepo en la esencia en eso, porque no hay que esperar retribución.

(Presidente de directorio de empresa) 
Gráfico 19. AL REALIZAR APORTES SOCIALES, ¿HA SOLICITADO ESTUDIOS QUE MIDAN EL IMPACTO REAL DEL PROYECTO O INSTITUCIÓN BENEFICIADA?

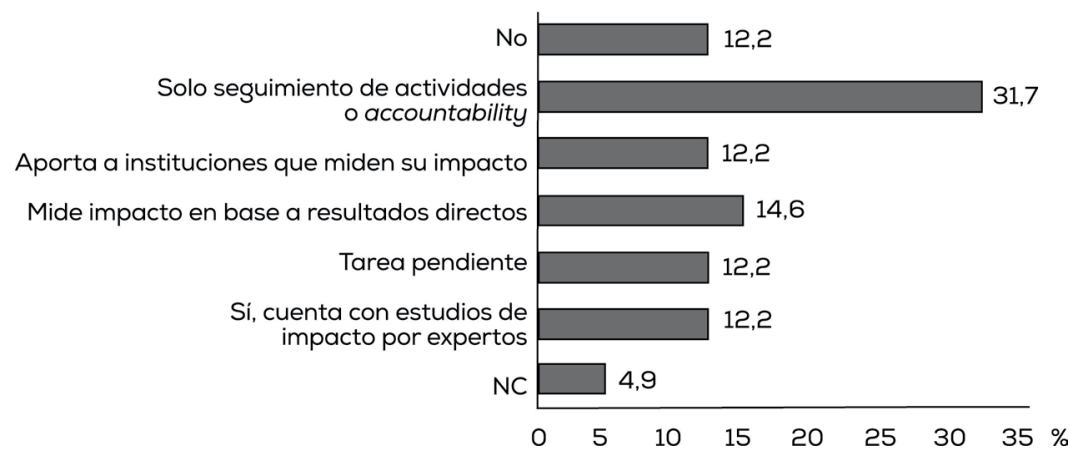

Fuente: CEFIS UAI 2015.

Sin embargo, aquellos empresarios que tienen una fundación propia o familiar han incorporado con mayor énfasis sistemas de medición de resultados, ya sea a través de reportes según resultados directos (ejemplo, variación en el Simce en proyectos educacionales o cantidad de prestaciones de salud versus costo) o bien a través de contratación de estudios de rentabilidad social con expertos:

Para mí, éste es el gran tema. Es fácil mirarse el ombligo, qué bonitas exposiciones, llegan 30 mil personas. ¿Es mucho o poco? ¿Vale la pena o no? ¿Qué pasa si, en vez de a nuestra fundación, le entregamos los recursos a la fundación X? No tenemos esa evaluación y eso es una preocupación. ¿Qué valor le estamos dando a este aporte que estamos haciendo?

(Presidente de directorio, preside fundación familiar)

Queremos tener el mayor impacto y de la mejor forma, dados los recursos que estamos involucrando. Cualquier actividad social en ese sentido tiene parámetros distintos, pero a nosotros nos interesa que esto tenga visión de largo plazo y cambiar la vida a las personas. Para eso hay que medir el impacto, y si algo no funciona, ajustarlo. Esto tiene que de alguna manera cambiar la vida de las personas.

(Presidente de directorio, participa en fundación familiar) 


\subsection{El marco institucional: los incentivos tributarios a las donaciones}

En Chile, a partir de la década de 1990 se legisló respecto de una serie de incentivos tributarios que se concentraron, primero, en las donaciones destinadas a organizaciones sin fines de lucro, con objetivos culturales y educacionales (escolar y universitario). Con el tiempo, estos incentivos se ampliaron a organizaciones relacionadas con la pobreza y la discapacidad y el ámbito deportivo, y más tarde se amplió el tipo de contribuyente que puede obtener beneficios por sus donaciones. ${ }^{21}$ Estos incentivos han significado un impulso relevante para el desarrollo de las organizaciones sin fines de lucro, al estimular las donaciones por parte de privados. También han sido un factor articulador de lo que la literatura denomina "economía de la caridad", modelando el costo que las donaciones tienen efectivamente para el donante (Irarrázaval y Guzmán 2000, 14).

En ese sentido, han existido diversas iniciativas legales que proponen unificar el sistema. Como señala el mensaje del proyecto de ley que crea un régimen unificado para los beneficios tributarios por donaciones efectuadas a entidades sin fines de lucro, ingresado al Congreso Nacional el 6 de marzo de 2014 (Boletín número 9266-05), "la gran diversidad de normativas existentes y el aislamiento en el que cada una de ellas fue concebida, ha derivado en una legislación fragmentada, dispersa, heterogénea y poco coordinada. Esto presenta naturalmente dificultades a potenciales donantes y donatarios para operar con estos mecanismos, atenta contra la transparencia de los mismos y deja espacios abiertos para irregularidades en su utilización. También da lugar a arbitraje por parte de los donantes, quienes terminan usando el régimen más simple o aquel que les reporta mayores beneficios".

Si bien los incentivos tributarios no aparecen mencionados entre los factores motivacionales que mencionan los empresarios para realizar aportes filantrópicos, el 32 por ciento de ellos señala que los incentivos tributarios son relevantes en el proceso de intercambio entre donante y donatario, ya sea como factor de decisión respecto del monto máximo de los aportes financieros o para definir el apoyo a un determinado proyecto sobre otro. Aquellos que no lo consideran del

21 Se han identificado 58 disposiciones legales que contienen beneficios excepcionales para las donaciones, en su mayoría artículos aislados dentro de cuerpos legales de diversa materia. Para conocer las principales, ver nota 1. 
todo determinantes en el proceso de toma de decisiones aducen razones relacionadas con una visión crítica del uso del sistema, más que con la irrelevancia de los incentivos:

Son varias leyes distintas, complejas y entonces hay que hacer toda una ingeniería. En vez de facilitar, acá todo es complicado. Las empresas que tienen más recursos destinan más plata, lo que está mal porque son sólo una parte y son muchas más las empresas que pueden colaborar.

(Presidente de directorio, líder grupo empresarial, participa en fundación)

Las personas naturales no aportan hoy porque tienen temores. Cuando he aportado como persona no lo hago contra impuestos, lo hago personal, porque cada vez que aportas te retienen la declaración de impuestos.

(Socio fundador de empresa)

Esta visión crítica del sistema es extendida entre los empresarios. Sus falencias se señalan como una traba para el escalamiento de donaciones (gráfico 20).

\section{Gráfico 20. OPINIONES SOBRE LA LEGISLACIÓN VIGENTE EN INCENTIVOS TRIBUTARIOS A LAS DONACIONES}

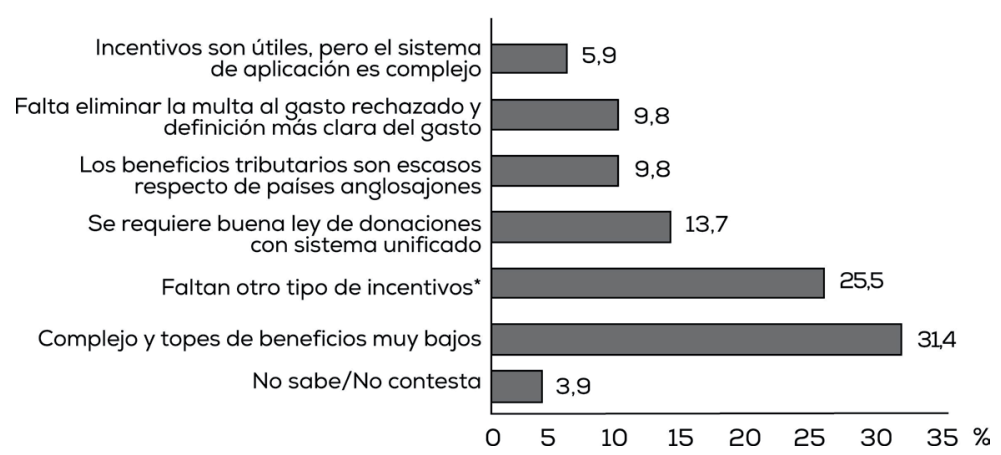

*= Este item se relaciona con ausencia de incentivos relevantes y útiles para donaciones de personas naturales, endowments y/o fondos de inversión social.

Nota: El 24 por ciento de los entrevistados señaló dos opiniones. Los porcentajes se calculan sobre el total de respuestas.

Fuente: CEFIS UAI 2015. 
El 25,5 por ciento de respuestas referidas a la falta de otros incentivos se relaciona con beneficios para personas naturales, fundaciones familiares, endowments o fondos de inversión social. Por otra parte, el 12 por ciento de los entrevistados mencionó la necesidad de definir incentivos a las donaciones para las sociedades de inversión:

Habría un gran cambio si a las personas naturales se les diera un beneficio relevante en las donaciones respecto de los impuestos que ellas pagan. Cuando una persona dona, tiene un impuesto a la donación que, en la práctica, significa reemplazar el impuesto a la herencia. (...) Si tuviéramos una buena ley de donaciones para estimularlas, sería genial. Es lo que hay en Estados Unidos, donde todos tienen fundaciones y puedes disponer de los bienes en vida y que perduren a través de los trusts, que no tenemos acá. Se podría desarrollar aquí una buena ley de donaciones, tanto para las empresas como para las personas.

(Director de empresas)

Las legislaciones que regulan los incentivos tributarios para fines deportivos, sociales, culturales, universitarios y establecimientos educacionales municipalizados contemplan beneficios, tanto para contribuyentes de primera categoría (empresas) como para contribuyentes de global complementario (personas). Sin embargo, la visión de los empresarios es que las personas carecen de incentivos suficientes ${ }^{22}$ y debiera fortalecerse su participación en el sistema de donaciones (gráfico 21). ${ }^{23}$ Hay que considerar que si bien el incentivo para todos los contribuyentes está limitado respecto del alcance de los montos a donar (por el Art. 10 de la Ley n. ${ }^{0} 19.885$ que incentiva y norma el buen uso de donaciones), esta restricción parece mayor para los contribuyentes individuales. Mientras las empresas pueden acoger a incentivos las donaciones hasta el 5 por ciento de la renta líquida imponible, para los contribuyentes del impuesto global complementario y para los contribuyentes del impuesto único de segunda categoría se aplica cada año un límite global absoluto

${ }^{22}$ Cabe destacar que la Ley de Donaciones con Fines Educacionales (Art. $3^{\circ}$ de la Ley n. $^{\circ}$ 19.247) no contempla beneficios para contribuyentes del global complementario. El ámbito de la educación es uno de los principales focos de destino de las donaciones señalados por los entrevistados (ver gráfico 14).

${ }^{23}$ Recordemos que en Estados Unidos los individuos representan el 72 por ciento de los donantes (Giving USA Report 2014). 
equivalente al 20 por ciento de la renta imponible o a 320 unidades tributarias mensuales, si este monto fuera inferior a dicho porcentaje.

Esta visión generalizada respecto de la necesidad de ampliar y fortalecer los incentivos para la participación de personas en donaciones filantrópicas se da en sintonía con aquella visión que señala que las empresas realizan inversiones sociales con lógica transaccional (reputación $\mathrm{u}$ otros fines relacionados con la sustentabilidad del negocio):

Los incentivos debieran estar más enfocados en las personas y sus sociedades de inversión y fundaciones familiares, no en las empresas. Éstas debieran tener otro tipo de incentivos. Dado que la RSE son acciones necesarias para mejorar el valor de la empresa, entonces debiera ser un gasto como cualquier otro. Es decir, al no tener incentivos tributarios específicos debieran aceptarse como gasto. Pero en Chile es todo al revés. Las empresas tienen incentivos y las personas no.

(Presidente de directorio, líder de grupo empresarial y de fundación)

Debieran cambiar los beneficios tributarios para las personas. Las empresas están bien, pero si uno dona plata no aparece en tu pago de impuestos. Es muy caro dar como persona natural. Una

Gráfico 21. ¿CREE USTED QUE LOS INCENTIVOS TRIBUTARIOS PARA DONAR CON FINES SOCIALES DEBIERAN ESTAR MÁS ENFOCADOS EN LAS EMPRESAS, LAS PERSONAS, O EN AMBAS?

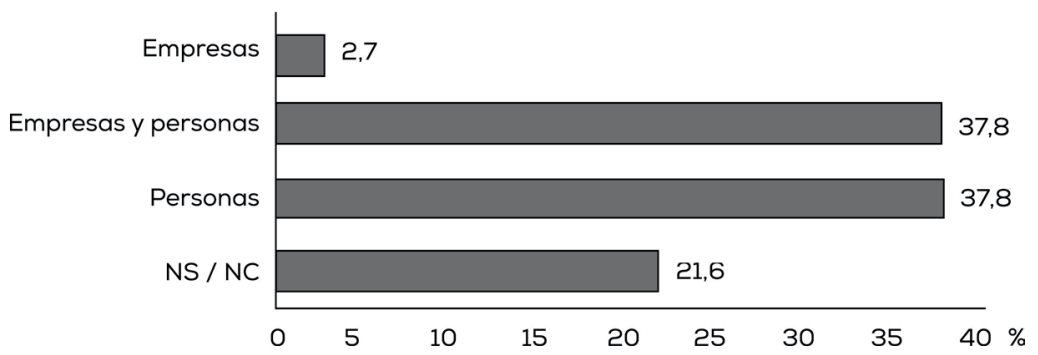

Nota: Por problemas de tiempo, esta pregunta se aplicó al 90 por ciento de los encuestados. Los porcentajes se calculan sobre el total de entrevistados a los que si se les aplicó la pregunta.

Fuente: CEFIS UAI 2015. 
ley única sería más fácil en ese sentido. De todas maneras hay que buscar el típico equilibrio, que sea útil y que sea bueno, y que no se preste para abusos. Habría un gran cambio si a las personas naturales se les diera un beneficio relevante respecto de los impuestos que ellas pagan en las donaciones.

(Gerente general de empresa)

\section{CONCLUSIONES}

El presente trabajo analiza el fenómeno filantrópico desde la visión de los empresarios chilenos, abordando una visión mutidimensional del concepto e inquiriendo sobre la percepción y práctica de sus aportes sociales en el ámbito de las motivaciones, las intenciones, los beneficiarios, el proceso de intercambio, los resultados obtenidos, y un ámbito específico del marco institucional (los incentivos tributarios). El estudio entrega información relevante a ser considerada para una estimación del potencial de crecimiento del fenómeno en Chile, que debe integrar otros factores de índole económica. También identifica ámbitos institucionales necesarios a considerar a la hora de impulsar su desarrollo. Con todo, tiene las limitaciones propias de un estudio inicial, que requiere profundizar en los respectivos temas que emergen en la práctica filantrópica, tanto a nivel del universo abordado como con otras fuentes documentales que permitan corroborar la praxis del empresariado en este ámbito.

Los resultados permiten identificar, en primer lugar, ciertos patrones indicadores de la relevancia que la filantropía tiene para los empresarios, especialmente en las dimensiones relacionadas con las motivaciones e intenciones. Ambas dimensiones se manifiestan en este estudio relacionadas mayoritariamente con el deber moral y la tradición familiar. En el señalado rechazo a identificarse con el concepto de caridad se vislumbra una aversión a una donación reactiva y una disposición a un mayor involucramiento en ciertos ámbitos de aportes sociales. El estudio permite identificar una correlación entre mayor formalización de la estructura de donación y mayores presupuestos destinados a fines filantrópicos, así como mayor implementación de sistemas de medición de resultados, correlación que una investigación sobre filantropía institu- 
cional permitiría explicar en mayor profundidad. En la misma línea, colaboraría la existencia de una agencia pública que unificara los registros de donantes y donatarios y los montos involucrados con distintos fines, generando no sólo material de investigación, sino también prácticas de transparencia y buen uso.

En el ámbito de los beneficiarios, el estudio identifica una carencia en la percepción del nivel profesional de los donatarios y, sin embargo, una positiva percepción de la figura del emprendedor social. La literatura ha identificado una relación positiva entre reputación de las organizaciones sin fines de lucro y confianza y disposición a donar de los donantes, reconociendo la relevancia que las estrategias de comunicaciones tienen en los donantes de alto patrimonio (Torres-Moraga et al. 2010, 171-172), análisis que debiesen incorporar los donatarios entre sus ámbitos de gestión.

La familia empresaria no sólo cumple un rol en el ámbito de la motivación, sino también en el proceso de intercambio. En este ámbito, la práctica filantrópica de los empresarios es aún incipiente si se evalúa según los componentes básicos de la corriente filantrópica estratégica; esto es, la definición clara de objetivos, diseño de estrategias en base a información y a datos, rendición periódica de cuentas y evaluaciones rigurosas. Una de las carencias que evidencia este estudio es que la búsqueda de información en base a datos objetivos para la toma de decisiones respecto de los aportes es poco extendida entre el empresariado chileno, especialmente en el ámbito de evaluación de resultados intermedios (outcomes) y de impacto. De hecho, la evaluación de impacto y su difusión para generar y compartir conocimiento son temas emergentes dentro del mundo fundacional, pero aún varios de sus actores lo ven como un ámbito que compite con los recursos destinados a los proyectos y a los beneficiarios (Villar 2015, 128). Sin embargo, es importante tener en consideración que la demostración del impacto filantrópico se ha señalado como piedra fundamental para legitimar la filantropía a nivel de gobierno y sociedad e incrementar su práctica a través de nuevos participantes (HICS y UBS 2015, 51).

En segundo lugar, la visión crítica que manifiesta un subgrupo de empresarios respecto de donaciones a través del canal empresarial hace necesario analizar con mayor profundidad los alcances de las prácticas de filantropía corporativa en el ecosistema local. Se requiere también un 
análisis crítico respecto de las prácticas y exigencias de retorno de la inversión y la pérdida de centralidad de la solidaridad como valor guía en las estrategias de inversión social privada (Villar 2015, 70). Asimismo, se ha identificado un impacto positivo de la práctica de transparencia en la legitimación de fundaciones empresariales ante stakeholders externos y la sociedad en general (Rey et al. 2012, 87). Ambos ámbitos — transparencia y motivación - son puntos de interés para investigar en el ámbito de la filantropía corporativa en el contexto chileno.

Por último, como una pieza del marco institucional, el sistema de incentivos a las donaciones existente en Chile es un instrumento sobre el cual los empresarios poseen una opinión crítica, y emerge como un punto relevante dentro de las carencias y trabas para la articulación de un ecosistema filantrópico fortalecido. Estos resultados sugieren que un cambio que tienda a la simplificación del sistema para los donantes contribuiría al escalamiento de los aportes filantrópicos. Sin embargo, surge la necesidad de un análisis en profundidad de las falencias del sistema vigente, del tipo de contribuyente a incorporar en los incentivos y de la utilidad de marcos legales para instrumentos de poco uso en Chile (trusts, endowments, community foundations), para que estos sean efectivos e incidentes en fortalecer el ecosistema y aumentar la cantidad de participantes, sea que se trate de empresas, familias o individuos en las distintas categorías de contribuyentes. Cualquier propuesta en este sentido debe tener en consideración la legitimidad social de estos instrumentos, ${ }^{24}$ ya que la sociedad espera que el incentivo fiscal se traduzca en una creación de valor social que supere el costo de oportunidad que supone para las arcas públicas (Rey 2013b, 200).

La profesionalización tanto de donatarios como de los donantes, la investigación de este campo, el acceso a datos confiables para su análisis y la generación de conciencia del rol que tiene la filantropía en la cohesión social y en el fortalecimiento de la democracia son parte de los factores necesarios para articular un ecosistema de filantropía en Chile realmente incidente en el desarrollo económico y social. Este estudio contribuye desde el ámbito de uno de los actores del ecosistema, los empresarios, aportando un análisis de las múltiples dimensiones que influyen en su visión y práctica de la filantropía.

${ }^{24}$ Según el Estudio de Opinión Pública de Donaciones Empresariales (CEFIS UAI, 2015), el 43 por ciento de los ciudadanos está de acuerdo con que una parte del monto donado por empresas o sus dueños a áreas sociales pueda ser descontada de impuestos. El 50 por ciento está en desacuerdo con ello. 


\section{REFERENCIAS CITADAS}

Berger, Gabriel, Nicolás Ducoté \& Lorena Reiss. 2004. Filantropía individual en la Argentina. Estudio de opiniones, actitudes y comportamiento filantrópico de personas de alto patrimonio. Buenos Aires: Centro para la Implementación de Políticas Públicas para la Equidad y el Crecimiento (CIPPEC).

Bishop, Mathew \& Michael Green. 2009. Filantrocapitalismo. Cómo los ricos pueden cambiar el mundo. Buenos Aires: Tendencias Editores.

Ceja, Lucía, Remei Agulles \& Josep Tàpies Lloret. 2010. "The importance of values in family-owned firms". Working Paper 875. IESE Business School, Universidad de Navarra. http://www.iese.edu/research/pdfs/DI-0875-E.pdf.

CEFIS UAI - Centro Filantropía e Inversiones Sociales. 2015. "Estudio de Opinión Pública: percepción ciudadana de las donaciones sociales empresariales. Julio 2015”. Universidad Adolfo Ibáñez. www.escueladegobierno.uai.cl/centros/ cefis/.

Chen, Jennifer C., Dennis M. Patten \& Robin W. Roberts. 2008. "Corporate Charitable Contributions: A Corporate Social Performance or Legitimacy Strategy?" Journal of Business Ethics 82: 131-144. doi: 10.1007/s10551-0079567-1.

Coatsworth, John H. 2008. "Movilizando tiempo y dinero: la filantropía y el déficit social en América Latina". En Filantropía y cambio social en América Latina, editado por Cynthia Sanborn \& Felipe Portocarrero. Lima: Centro de Investigación de la Universidad del Pacífico \& David Rockefeller Center for Latin American Studies.

Credit, Suisse. 2014. Global Wealth Report 2014. Zurich: Research Institute. https:// publications.credit-suisse.com/tasks/render/file/?fileID=60931FDE-A2D2-F568B041B58C5EA591A4.

Durán, Patricio. 2015. "Strategy and performance of family firms: An institutional embeddedness perspective”. $\mathrm{PhD}$. dissertation. University of South Carolina.

Encuesta Nacional Bicentenario UC - Adimark. 2015. Centro de Políticas Públicas UC.

Fukuyama, Francis. 1996. Confianza. Buenos Aires: Editorial Atlántida.

Giving USA. 2014. The Annual Report on Philanthropy for the Year 2013 (executive summary). Chicago: Giving USA Foundation. www. givingusa.org.

HICS \& UBS - Hauser Institute for Civil Society (Harvard University) \& UBS Philanthropy Advisory. 2015. De la prosperidad al propósito. Perspectivas sobre la filantropía y la inversión social entre las personas de alto nivel patrimonial en América Latina. Zurich: Hauser Institute.

Irarrázaval, Ignacio \& Julio Guzmán. 2000. “Incentivos tributarios para instituciones sin fines de lucro: análisis de la experiencia internacional”. Estudios Públicos 77: 203-272. 
Irarrázaval, Ignacio \& Julio Guzmán. 2008. “¿Mucho o muy poco? El rol de los incentivos tributarios en la promoción de la filantropía”. En Filantropía y cambio social en América Latina, editado por Sanborn \& Portocarrero.

Irarrázaval, Ignacio, Eileen Hairel, Wojciech Sokolowski \& Lester Salamon. 2006. "Estudio comparativo del sector sin fines de lucro - Chile". Santiago de Chile: Johns Hopkins University, PNUD y Focus.

Kania, John, Mark Kramer \& Patty Russel. 2014. "Strategic Philanthropy for a Complex World”. Stanford Social Innovation Review (summer): 26-37.

Machado, Felipe. 2010. "Fundaciones en Chile. Bases para una propuesta de cambio normativo". Documento de trabajo, Centro de Políticas Públicas UC.

Noonan, Kathleen \& Katherina Rosquetta. 2008. “'I'm not Rockefeller'. 33 High Net Worth Philanthropist Discuss their Approach to Giving”. The Center for High Impact Philanthropy, School of Social Policy \& Practice, Pennsylvania University.

OECD. 2014. Society at a Glance 2014: OECD Social Indicators. OECD Publishing.

Ponce de León, Macarena. 2011. Gobernar la pobreza. Prácticas de caridad y beneficencia en la ciudad de Santiago, 1830-1890. Santiago de Chile: Editorial Universitaria, Dirección de Bibliotecas, Archivos y Museos \& Centro de Investigaciones Diego Barros Arana.

Porter, Michael \& Michael Kramer. 2011. "Creating shared value". Harvard Business Review (January-February): 3-18.

Putnam, Robert, 1993. Making Democracy Work: Civic Tradition in Modern Italy. Princeton: Princeton University Press.

Quick, Elaine, Toni Ann Kruse \& Adam Pickering. 2014. Rules to Give By. A Global Philanthropy Legal Environment Index. Charities Aid Foundation, Nexus \& McDermott Will \& Emery LLP.

Rey, Marta. 2013a. "Filantropía y participación cívica en el albor del siglo XXI". Revista ICE 872: 7-18. http://www.revistasice.com/CachePDF/ICE_872_ 42 ADB6F8BDE04BAECA54825E166A6E1E.pdf.

—. 2013b. "Filantropía, familia, empresa: cómo convertirlas en un triángulo virtuoso". En La suerte de dar, editado por Carmen Reviriego, 179-201. Barcelona: Plataforma Editorial. doi: 10.13140/2.1.1716.0480.

Rey, Marta, Javier Martin-Cavanna \& Luis Ignacio Álvarez. 2012. “Assessing and Advancing Foundation Transparency: Corporate Foundations as a Case Study". The Foundation Review 4 (3): 77-89. doi: 10.4087/ foundationreview-d-12-00003.1.

Rivera, Matías. 2010. "A Comparative Study of individual Philanthropy in the U.S. and Chile". Tesis de grado, Escuela de Ingeniería, Pontificia Universidad Católica de Chile. 
Rodin, Judith \& Margot Brandenburg. 2014. The Power of Impact Investing. Putting Markets to Work for Profit and Global Good. Philadelphia: Wharton Digital Press.

Sanborn, Cynthia \& Felipe Portocarrero. 2008. "Introducción”. En Filantropía y cambio social en América Latina, editado por Sanborn \& Portocarrero.

Shavelson, Richard, Judith Hubner \& George Stanton. 1976. "Self Concept: Validation of Construct Interpretation". Review of Educational Research 46 (3): 407-441.

Sokolowski, S. Wojciech. 2012. "Effects of Government Support of Nonprofit Institutions on Aggregate Private Philanthropy: Evidence from 40 Countries". Voluntas: International Journal of Voluntary and Nonprofit Organizations 24 (2): 359-381. doi: 10.1007/s11266-011-9258-5.

Sorman, Guy. 2014. El corazón americano. Ni el Estado, ni el mercado: la opción filantrópica. Barcelona: Editorial Debate.

Torres-Moraga, Eduardo, Arturo Vásquez-Parraga \& Cristóbal Barra. 2010. "Antecedents of Donor Trust in an Emerging Charity Sector: The Role of Reputation, Familiarity, Opportunism and Communication”. Transylvanian Review Administrative Science 29E (February): 159-177.

Villar Gómez, Rodrigo, coord. 2015. Recursos privados para la transformación social: filantropía e inversión social privada en América Latina hoy: Argentina, Brasil, Colombia y México. Colombia: Grupo de Fundaciones y Empresas (GDFE), Grupo de Institutos, Fundaciones y Empresas (GIFE), Asociación de Fundaciones Empresariales (AFE) \& Centro Mexicano para la Filantropía (CEMEFI).

\section{Anexo 1.}

\section{LISTA DE ENTREVISTADOS PARA ESTUDIO CEFIS UAI 2015}

Juan Francisco Lecaros Menéndez, Nicola Schiess, Juan José Cueto, George Anastassiou, Nicolás Hurtado Vicuña, Eduardo Gras, Felipe del Río, Eduardo Fernández León, Paulo Bezanilla, Eduardo Muñoz, Jaime Said Handal, Felipe Briones, Luis Enrique Yarur, Sergio Icaza, Juan Manuel Santa Cruz, Carlo Solari, Juan Andrés Camus, Horacio Pavez, Roberto Izquierdo, José Cox, Patricia Matte, Paola Luksic, Jorge Marín, Heike Paulmann, Bruno Philippi, Fernando Larraín Peña, Ricardo Massú, José Said, Juan Manuel Casanueva, Catalina Saieh, Pablo Echeverría, Aníbal Montero, Pedro Donoso, Richard von Appen, José Antonio Garcés, Eliodoro Matte, Juan Obach, Sergio Cardone, Arturo Claro, Roberto Angelini y Alfonso Swett Opazo. 
Anexo 2.

ESTRUCTURA CONTENIDOS DE CUESTIONARIO ESTUDIO CEFIS UAI 2015.

\begin{tabular}{|c|c|}
\hline \multirow[t]{4}{*}{ Percepción general } & rol social de los empresarios \\
\hline & aportes sociales de las empresas \\
\hline & filantropia en Chile \\
\hline & filantropia y confianza \\
\hline \multirow[t]{7}{*}{ Dimensiones de los aportes sociales } & motivación \\
\hline & $\begin{array}{l}\text { toma de decisión: participación de terceros } \\
\text { y/o hijos }\end{array}$ \\
\hline & $\begin{array}{l}\text { sistema de canalización de aportes sociales y } \\
\text { estructura /fundaciones/ empresas, ámbitos } \\
\text { de inversión }\end{array}$ \\
\hline & autodefinición y reconocimiento público \\
\hline & $\begin{array}{l}\text { percepción de beneficiarios: organizaciones } \\
\text { sociales, emprendedores sociales, fondo de } \\
\text { inversiones de impacto }\end{array}$ \\
\hline & medición de impacto \\
\hline & $\begin{array}{l}\text { presupuesto filantrópico: definición, monto, } \\
\text { proyección y herencia }\end{array}$ \\
\hline Marco institucional & incentivos tributarios \\
\hline
\end{tabular}

